\title{
Water Activities and Osmotic Coefficients of Aqueous Solutions of Five Alkyl-Aminium Sulfates and Their Mixtures with $\mathrm{H}_{2} \mathrm{SO}_{4}$ at $25{ }^{\circ} \mathrm{C}$
}

\begin{tabular}{|r|l|}
\hline Journal: & Aerosol Science \& Technology \\
\hline Manuscript ID: & AST-MS-2014-196 \\
\hline Manuscript Type: & Original Manuscript \\
\hline Date Submitted by the Author: & 23-Oct-2014 \\
\hline Complete List of Authors: & $\begin{array}{l}\text { Sauerwein, Meike } \\
\text { Clegg, Simon } \\
\text { Chan, Chak }\end{array}$ \\
\hline Keywords: & $\begin{array}{l}\text { amine sulfate salts, amiunium sulfates, water activity, osmotic coefficient, } \\
\text { extended ZSR }\end{array}$ \\
\hline & \\
\hline
\end{tabular}

\section{SCHOLARONE \\ Manuscripts}




\section{Water Activities and Osmotic Coefficients of Aqueous Solutions of Five Alkyl-Aminium Sulfates and Their Mixtures with $\mathrm{H}_{2} \mathrm{SO}_{4}$ at $25{ }^{\circ} \mathrm{C}$}

Running Title: "Water activities of aqueous alkylaminium sulfates"

Meike Sauerwein ${ }^{1}$, Simon L. Clegg ${ }^{2, *}$, and Chak K. Chan ${ }^{1,3, *}$

${ }^{1}$ Division of Environment, Hong Kong University of Science and Technology, Clear Water Bay, Kowloon, Hong Kong

${ }^{2}$ School of Environmental Sciences, University of East Anglia, Norwich NR4 7TJ, U.K.

${ }^{3}$ Department of Chemical Engineering, Hong Kong University of Science and Technology, Clear

Water Bay, Kowloon, Hong Kong

*Corresponding author: sclegg@uea.ac.uk; keckchan@ust.hk 


\section{INTRODUCTION}

Short chain aliphatic amines such as methyl- and ethyl-amines are alkaline, volatile, water soluble organic compounds. Despite their low average ambient concentrations of about $10-100$ ppt in the gas phase (Ge et al. 2011a), and high pure liquid vapor pressures (Ge et al. 2011b), they are able to substantially enhance the formation of secondary aerosols (Murphy et al. 2007; Kurtén et al. 2008; Almeida et al. 2013). Maximum mass loadings of short chain alkyl-amine ions, accounting for up to several hundred $\mathrm{pg} \mathrm{m}^{-3}$, have been detected in the accumulation mode of atmospheric aerosols (Müller et al. 2009; VandenBoer et al. 2011), and showing a strong dependence on relative humidity $(R H), \mathrm{pH}$ and temperature (Pratt et al. 2009; Rehbein et al. 2011).

Major pathways of amine removal from the gas phase include photo-oxidation processes (Nielsen et al. 2012), gas-particle partitioning via acid-base reactions (Wang et al. 2010; Rehbein et al. 2011; Liu et al. 2012), and the displacement of ammonia from ammonium salts under elevated amine gas phase concentrations (Lloyd et al. 2009; Bzdek et al. 2010; Qiu et al. 2011; Chan and Chan, 2012). The resulting alkyl-ammonium (aminium) salts - including sulfates, nitrates (Pratt et al. 2009), and carboxylates (Smith et al. 2010) - can promote particle growth and cloud droplet formation. Re-volatilization of amines from the particle phase has been observed for aminium nitrates (Murphy et al. 2007), as well as for certain secondary and tertiary aminium sulfates (Chan and Chan, 2013).

Our current understanding of the chemical and physical properties of aminium sulfates is far less developed than for ammonium sulfate. Recent studies have explored characteristics of dry and aqueous methyl- and ethyl-aminium sulfates including their densities and thermostability (Qiu and Zhang, 2012; Lavi et al. 2013; Clegg et al. 2013), hygroscopic and crystallization behavior (Qiu and Zhang, 2012; Chan and Chan, 2013), as well as the ability to act as cloud condensation nuclei (CCN) (Lavi et al. 2013). Methyl- and ethyl-aminium sulfates appear to have hygroscopic growth factors (based upon particle radius) that differ significantly from those of ammonium sulfate over a wide range of $R H$, with decreasing growth factors as the number of alkyl-group carbons increase (Qiu and Zhang, 2012). When converted to water uptake on a molar basis these results are much closer to those for $\left(\mathrm{NH}_{4}\right)_{2} \mathrm{SO}_{4}$ (Clegg et al. 2013, Fig. 7c), but the scatter in the data make it difficult to draw firm conclusions or clearly differentiate the behavior of one salt from another. In drying experiments using an electrodynamic balance, supermicron droplets of primary methyl- and ethyl-aminium sulfates formed stable crystals, while the secondary and tertiary amines showed non-crystalline or liquid phase states even under dry conditions (Chan and Chan, 2013). Furthermore, secondary and tertiary alkyl-amines (re-)evaporated from aminium sulfate particles upon drying at room temperature under amine-free gas phase conditions. For instance, trimethylamine sulfate droplets with an initial molar aminium:sulfate ratio of 2:1 was found to have a stochiometric ratio of 1:1 under dry amine-free conditions (Chan and Chan, 2013). This observation demonstrates the need to minimize or correct for amine evaporation in studying these salts, especially under low $R H$ conditions. 
Water and solute activities in aqueous aerosols are needed in order to calculate gas/liquid/solid partitioning in the atmosphere and understand the role of aerosols in atmospheric processes. The behavior of mixtures containing common inorganic salts, acids, and bases is relatively well understood and a number of models of their equilibrium thermodynamic properties have been developed (e.g., Zhang et al. 2000; Wexler and Clegg, 2002; Fountoukis and Nenes, 2007; Zuend et al. 2011). However, present knowledge of amines and aminium salts is limited. There have been a few studies of osmotic coefficients of aminium chlorides (Macaskill and Bates, 1986) and nitrates (Bonner 1981), but there are no direct measurements of water activities of aminium sulfates or their mixtures with other solutes. In the Extended Aerosol Inorganics Model (E-AIM, Wexler and Clegg, 2002), it assumed that aminium cations interact with anions in the same way as ammonium, $\mathrm{NH}_{4}{ }^{+}$(Clegg et al. 2013). The accuracy of this approximation is not known.

Besides the commonly used isopiestic method of measuring water activities (e.g. Rard and Platford, 1991), direct static and direct dynamic methods exist (Blandamer et al. 2005). In studies of aerosols in the laboratory, electrodynamic balances and hygroscopic tandem differential mobility analyzers (HTDMAs) have often been deployed to indirectly determine the relationship between concentration and water activity. These aerosol techniques can cover a wide range of relative humidities and allow measurements of solutions supersaturated with respect to the dissolved solutes. To account for the possibility of evaporative losses of solute, Peng and Chan (2001) and Lightstone et al. (2000) have described correction techniques for carboxylic acids and ammonium nitrate. However, amine evaporation, which is to be expected for the salts of secondary and tertiary methyl- and ethylamines, can lead to mass decreases of the total solute in the case of nitrate and chloride salts and changes in the aminium:sulfate ratio in the case of sulfate salts. This poses a challenge to measuring water activities of aqueous aminium sulfates while maintaining a constant aminium:sulfate ratio.

In this work water activities $\left(a_{\mathrm{w}}\right)$ have been measured for mixtures of sulfuric acid and five alkylaminium sulfates of high atmospheric relevance: methylaminium sulfate (MAS), ethylaminium sulfate (EAS), dimethylaminium sulfate (DMAS), diethylaminium sulfate (DEAS), and trimethylaminium sulfate (TMAS), for various aminium:sulfate molar ratios at $25{ }^{\circ} \mathrm{C}$. By using bulk solutions in the experiments the potential evaporation of amines during the measurements was minimized relative to other methods (Chan and Chan, 2013). (In contrast to aerosols, a bulk solution has a low surface area to volume ratio resulting in much less evaporation, at the expense of the ability to study supersaturated solutions.) Measurements were made at four different aminium:sulfate molar ratios (approximately $0.5: 1,1: 1,1.5: 1$ and 2:1) for mixtures containing each amine. To facilitate comparison of the results of this study and those of Clegg et al. (2013) at molar ratios of 2:1 (aminium sulfate), and to enable water activities to be calculated for any ratio, we have interpolated the experimental data to fixed water activities and fitted the values with an extended 
Zdanovskii-Stokes-Robinson equation (Clegg et al. 2003). We have also used the ion-interaction model of Pitzer, Simonson, and Clegg (Clegg et al. 1992) to represent osmotic and activity coefficients of the five pure aqueous aminium sulfates over a wide range of concentrations.

\section{THEORY}

\subsection{Osmotic coefficients}

Osmotic coefficients $(\phi)$ are related to water activities $\left(a_{\mathrm{w}}\right)$ according to the equation:

$$
\ln \left(a_{\mathrm{w}}\right)=-\left(\Sigma_{i} m_{\mathrm{i}} \cdot \phi \cdot M_{\mathrm{w}} / 1000\right)
$$

where $m_{\mathrm{i}}$ is the molality of ion or uncharged solute species ' $\mathrm{i}$ ' (in $\mathrm{mol} \mathrm{kg}^{-1}$ water), and $M_{\mathrm{w}}(\mathrm{g})$ is the molar mass of water (Robinson and Stokes, 1970). Because the distribution of total sulfate $\left(\mathrm{SO}_{4}{ }^{2-}\right.$ (tot) between $\mathrm{HSO}_{4}{ }^{-}$and $\mathrm{SO}_{4}{ }^{2-}$ forms in our experiments is not known, all osmotic coefficients presented in this work are stoichiometric or total values $\left(\phi_{\mathrm{st}}\right)$. These are related to the measured water activity by:

$$
\phi_{\mathrm{st}}=-\ln \left(a_{\mathrm{w}}\right) /\left(m_{\mathrm{st}} \cdot M_{\mathrm{w}} / 1000\right)
$$

where $m_{\mathrm{st}}$ is the stochiometric molality $m_{\mathrm{st}}=m \mathrm{H}^{+}$(tot) $+m \mathrm{CH}_{3} \mathrm{NH}_{3}{ }^{+}+m \mathrm{SO}_{4}{ }^{2-}$ (tot) (where $\mathrm{CH}_{3} \mathrm{NH}_{3}{ }^{+}$is the aminium ion of interest), or simply $3 \mathrm{mSO}_{4}{ }^{2-}$ (tot).

\subsection{Extended Zdanovskii-Stokes-Robinson (ZSR) model}

This is a widely used method of estimating the solvent content of solution mixtures from those of solutions of the individual pure solutes at the same solvent activity as the mixture (Stokes and Robinson, 1966). In the present study we have applied a simplified version of the extended ZSR approach of Clegg et al. (2003), see their Eq. 7, to represent water activities and osmotic coefficients of ternary mixtures of aminium sulfate $-\mathrm{H}_{2} \mathrm{SO}_{4}-\mathrm{H}_{2} \mathrm{O}$ ):

$$
W_{\text {tot }}=w_{\mathrm{a}}^{\mathrm{o}}+w_{\mathrm{as}}^{\mathrm{o}}+\left(n_{\mathrm{a}}+n_{\mathrm{as}}\right) x_{\mathrm{a}} x_{\mathrm{as}} \cdot A^{\mathrm{o}}
$$

where $W_{\text {tot }}$ denotes the total mass of water in the solution mixture, and $w^{\mathrm{o}}$ is the amount of water associated with the acid 'a' or aminium sulfate 'as' in a pure aqueous solution at the same water activity as the mixture. The molar amount of each solute present in the mixture is denoted by $n$, and the mole fractions of the two dry solutes are calculated as $x_{\mathrm{a}}=n_{\mathrm{a}} /\left(n_{\mathrm{a}}+n_{\mathrm{as}}\right)$ and $x_{\mathrm{as}}=n_{\mathrm{as}} /\left(n_{\mathrm{a}}+n_{\mathrm{as}}\right)$. We fitted Eq. 3 to the experimental results to determine the empirical parameter $A^{\mathrm{o}}$ and calculate the 
water amounts (in $\mathrm{kg} \mathrm{H} \mathrm{H}_{2} \mathrm{O}$ per mole of solute) associated with the pure aminium sulfate salt $\left(w_{\mathrm{as}}{ }^{\circ}\right)$ over a wide range of water activity.

\subsection{Ion interaction Model}

The Pitzer, Simonson, and Clegg thermodynamic model (Clegg et al. 1992) is a mole fraction based ion interaction model which can represent solvent and solute activities in pure solutions and mixtures to very high solute concentrations. We have fitted this model to the osmotic coefficients of the pure aqueous aminium sulfates determined in this study. The equation, for the water activity $a_{\mathrm{w}}$, is given below for a solution containing a single electrolyte solute $\left(\mathrm{M}_{v^{+}} \mathrm{X}_{v_{-}}\right)$and water:

$$
\begin{aligned}
& \ln \left(a_{\mathrm{w}}\right)=\ln \left(x_{\mathrm{w}}\right)+2 A_{\mathrm{x}} I_{\mathrm{x}}^{3 / 2} /\left(1+\rho I_{\mathrm{x}}^{1 / 2}\right)-x_{\mathrm{M}} x_{\mathrm{X}} B_{\mathrm{MX}} \exp \left(-\alpha \mathrm{I}_{\mathrm{x}}{ }^{1 / 2}\right) \\
& +x_{\mathrm{I}}^{2}\left(W_{\mathrm{w}, \mathrm{MX}}+\left(x_{\mathrm{I}}-x_{\mathrm{w}}\right) U_{\mathrm{w}, \mathrm{MX}}\right)+4 x_{\mathrm{w}} x_{\mathrm{M}} x_{\mathrm{X}}\left(2-3 x_{\mathrm{w}}\right) V_{\mathrm{w}, \mathrm{MX}},
\end{aligned}
$$

where $A_{x}$ is the mole fraction Debye-Hückel constant (2.917 at $\left.298.15 \mathrm{~K}\right), I_{x}$ is the ionic strength (equal to $0.5 \sum_{i} x_{i}\left|z_{i}\right|^{2}$ ), $\rho$ is a constant set equal to $13.0, x_{\mathrm{w}}$ denotes the mole fraction of water, and $x_{\mathrm{I}}$ denotes the total mole fraction of ions $\left(x_{\mathrm{M}}+x_{\mathrm{X}}\right)$. The coefficient $\alpha$ is equal to 13.0. The Debye-Hückel term (the second one on the first line of Eq. 4) describes the behavior of very dilute solutions. The model equation includes four fitted interaction parameters $B_{\mathrm{MX}}, W_{\mathrm{w}, \mathrm{MX}}, U_{\mathrm{w}, \mathrm{MX}}$ and $V_{\mathrm{w}, \mathrm{MX}}$, that describe mid- and short-range interactions between water, sulfate $(\mathrm{X})$, and aminium cations (M).

\section{METHODS}

Samples containing both sulfuric acid and each of the individual amines were prepared at four aminium:sulfate ratios of approximately $0.5: 1,1: 1,1.5: 1$ and 2:1. Because of the approximate concentrations of the amine stock solutions (see below) and unknown degree of evaporation of the amines during sample preparation, aminium and sulfate concentrations in the primary samples were measured by ion chromatography to determine the exact mole ratios. Water activities of the solutions, and their dilutions with water, were determined using a water activity meter using the chilled mirror dew point technique.

\subsection{Preparation of solutions and determination of mole ratios}

The stock solutions were prepared from concentrated sulfuric acid $\left(\mathrm{H}_{2} \mathrm{SO}_{4}, 95-98 \mathrm{wt} \%\right.$, Acros Organics), and concentrated amine solutions, to achieve the highest possible molar fractions of the solute (and lowest possible water contents) without requiring additional drying steps. The $\mathrm{H}_{2} \mathrm{SO}_{4}$ was titrated against standardized $\mathrm{NaOH}$ and found to have a concentration of $95.51 \pm 0.16 \mathrm{wt} \%$. 
Methylamine (MA, $37-43 \mathrm{wt} \%$ in $\mathrm{H}_{2} \mathrm{O}$, Aldrich), dimethylamine (DMA, $38-42 \mathrm{wt} \%$ in $\mathrm{H}_{2} \mathrm{O}$, Aldrich), and trimethylamine (TMA, $45 \mathrm{wt} \%$ in $\mathrm{H}_{2} \mathrm{O}$, Aldrich) were used without further treatment, while ethylamine (EA, $69-72 \mathrm{wt} \%$ in $\mathrm{H}_{2} \mathrm{O}$, Aldrich) and diethylamine (DEA, > $99 \mathrm{wt} \%$, Fluka) were diluted with ultrapure water $(18.2 \mathrm{~m} \Omega)$ to approximately $50 \mathrm{wt} \%$ before mixing with the $\mathrm{H}_{2} \mathrm{SO}_{4}$. Unique to the DEA system, we observed a mildly yellow color developing within a few hours upon dilution of $99 \mathrm{wt} \%$ DEA with ultrapure water. The color intensified when further mixed with $\mathrm{H}_{2} \mathrm{SO}_{4}$. Using ion chromatography (IC), no significant change in the $\mathrm{DEAH}^{+}$aminium ion concentration was detected, suggesting that only trace amounts of DEA reacted to form the yellow by-product.

The stock solutions of all the mixtures were prepared in a similar way to the following example. For the 2.0:1 dimethylaminium sulfate (DMAS) solution a mass of $4.0332 \mathrm{~g}$ of concentrated $\mathrm{H}_{2} \mathrm{SO}_{4}$ (containing $0.0393 \mathrm{~mol}$ of sulfate) was weighed into a glass container and immersed into an ice bath to cool for several minutes. Next, $9.4775 \mathrm{~g}$ of $40.0 \mathrm{wt} \%$ DMA solution (containing approximately $0.0841 \mathrm{~mol}$ of amine) was added drop-wise under continuous shaking in ice water. The mass of amine solution to be added was calculated from the stock solution concentrations, plus an additional few percent to compensate for potential amine evaporation during mixing. Finally, the stock solution was sealed and weighed again to determine the total amount of added amine solution. Further samples were prepared by diluting known masses from each stock solution with ultrapure water.

Despite constant cooling, amine evaporation during preparation of stock solutions could not be fully prevented. To determine the exact aminium:sulfate ratios, the aminium and sulfate contents of the stock solutions for each of the four ratios, and for mixtures containing each amine, were measured by ion chromatography (IC). We assumed that $\mathrm{H}_{2} \mathrm{SO}_{4}$ evaporation did not occur due to its extremely low volatility. Molalities of aminium and $\mathrm{H}^{+}$ion were calculated from the known mass of $95.51 \mathrm{wt} \%$ $\mathrm{H}_{2} \mathrm{SO}_{4}$ stock solution present (yielding the concentration of sulfate ion), and the molar aminium:sulfate ratio as determined by IC. Uncertainties in the ratio ranged between $1.2 \%$ and 5.8\%. In the case of the above mentioned DMAS example, the amount of dimethylaminium ion determined in this way accounted for $0.0769 \pm 0.0012$ mol of DMA. Molar amounts $(n)$ of total $\mathrm{H}^{+}$in each sample were calculated as $n \mathrm{H}^{+}=2 n \mathrm{SO}_{4}{ }^{2-}-n \mathrm{CH}_{3} \mathrm{NH}_{3}{ }^{+}$, where $\mathrm{CH}_{3} \mathrm{NH}_{3}{ }^{+}$represents any of the five aminium cations. The mass of water in each sample was calculated form the following formula: $(1.0-0.9551) \cdot \operatorname{mass} \mathrm{H}_{2} \mathrm{SO}_{4(\sim 95 \mathrm{wt} \% \text { stock })}+\left(\right.$ mass $\left.\mathrm{CH}_{3} \mathrm{NH}_{2(\sim 40 \mathrm{wt} \% \text { stock })}-\operatorname{mass} \mathrm{CH}_{3} \mathrm{NH}_{2}\right)+$ mass $\mathrm{H}_{2} \mathrm{O}_{\text {added }}$, where $\operatorname{mass} \mathrm{CH}_{3} \mathrm{NH}_{2}$ is the mass of amine present, calculated from the molalities of aminium, and mass $\mathrm{H}_{2} \mathrm{O}_{\text {added }}$ is the mass of water added to dilute the stock solution of the mixture to obtain the sample to be measured.

For the IC measurements aliquots of all solutions were diluted with ultrapure water to $1-10 \mathrm{mg} \mathrm{L}^{-1}$ (Metrohm, 881 compact IC Pro). The aminium cations were measured using a Metrosep C4 column and an eluent of $3.0 \mathrm{mM} \mathrm{HNO}_{3}, 0.14 \mathrm{mM}$ pyridine-2,6-dicarboxylic acid and $2 \%$ acetone; sulfate 
concentrations were determined by a DIONEX IonPac ${ }^{\circledR}$ AS14A column eluted with a $1.0 \mathrm{mM}$ $\mathrm{Na}_{2} \mathrm{CO}_{3}, 10.0 \mathrm{mM} \mathrm{NaHCO}$ solution. Cation and anion standards for IC calibration were prepared from amine hydrochlorides $\left(\mathrm{NH}_{2} \mathrm{CH}_{3} \mathrm{HCl} 99 \%, \mathrm{NH}\left(\mathrm{CH}_{3}\right)_{2} \mathrm{HCl} 99 \%, \mathrm{~N}\left(\mathrm{CH}_{3}\right)_{3} \mathrm{HCl} 98 \%\right.$, $\mathrm{NH}_{2} \mathrm{CH}_{2} \mathrm{CH}_{3} \mathrm{HCl} 98 \%, \mathrm{NH}\left(\mathrm{CH}_{2} \mathrm{CH}_{3}\right)_{2} \mathrm{HCl}$ 99\%, all from Sigma Aldrich, and dried under vacuum over $18 \mathrm{~h}$ at $333 \mathrm{~K})$, and ammonium sulfate $\left(\left(\mathrm{NH}_{4}\right)_{2} \mathrm{SO}_{4}>99 \%\right.$, Sigma Aldrich), respectively. As expected, the actual aminium:sulfate ratios measured by IC were lower than the nominal values because of amine evaporation due to the heat of mixing and their volatile nature,. For example the $\mathrm{TMAH}^{+}: \mathrm{SO}_{4}{ }^{2-}$ ratio of the stock that was prepared as $\sim 2: 1$ was found to be 1.78:1. Despite the evaporation during sample preparation, the aminium:sulfate ratios of the samples prepared in this study were still significantly higher (due to much lower losses of the amines) than those obtained by drying mixed dilute solutions (Chan and Chan, 2013).

\subsection{Water activity measurements}

A water activity meter (Aqua lab Series 3TE, Decagon devices, Inc.) was used to determine the water activities of bulk test solutions at $25.0 \pm 0.2^{\circ} \mathrm{C}$, by measuring the equilibrium relative humidities above the samples. The $R H$, expressed as a fraction, is related to the water activity $\left(a_{\mathrm{w}}\right)$ by:

$$
a_{\mathrm{w}}=p\left(\mathrm{H}_{2} \mathrm{O}\right) / p^{\mathrm{o}}\left(\mathrm{H}_{2} \mathrm{O}\right)=R H
$$

where $p\left(\mathrm{H}_{2} \mathrm{O}\right)$ is the equilibrium partial pressure of water above the solution, and $p^{\circ}\left(\mathrm{H}_{2} \mathrm{O}\right)$ the vapor pressure of pure water at the same temperature. The experimental uncertainty of the water activity measurements was estimated to be within \pm 0.003 . During the course of the experiments aminium:sulfate ratios of some of the samples were measured again, both before and after $a_{\mathrm{w}}$ determination, and found to be unchanged from those of the initial stock solutions (within experimental uncertainty). This confirmed that amine evaporation from the bulk samples was negligible. The measured water activities, and calculated osmotic coefficients, are listed in Table 1.

\section{RESULTS AND DISCUSSION}

In this section we present measured water activities and osmotic coefficients of aminium - $\mathrm{H}^{+}-\mathrm{SO}_{4}{ }^{2-}$ aqueous solutions, and describe trends from low to high aminium:sulfate ratios. We also compare values fitted using Eq. 3 to the measurements in order to evaluate the model's performance and the limits of its application to aminium sulfate systems. Osmotic coefficients of aminium sulfates and bisulfates obtained from the fitted Eq. 3 are then compared with those of their ammonium counterparts and literature data, and findings are discussed. Last, the results of parameterization of the ion interaction model (Eq. 4) are presented. 


\subsection{Changes of osmotic coefficient with increasing solute molality and aminium:sulfate ratios}

To illustrate the trends from aqueous $\mathrm{H}_{2} \mathrm{SO}_{4}$ solutions to the fully neutralised aqueous $\left.\left(\mathrm{CH}_{3}\right)_{\mathrm{n}} \mathrm{NH}_{4-\mathrm{n}}\right)_{2} \mathrm{SO}_{4}$ and $\left.\left(\mathrm{CH}_{3} \mathrm{CH}_{2}\right)_{\mathrm{n}} \mathrm{NH}_{4-\mathrm{n}}\right)_{2} \mathrm{SO}_{4}$, osmotic coefficients of solutions with different aminium:sulfate ratios are plotted against the square root of the sulfate molality in Fig. 1. Results for three aminium:sulfate molar ratios are shown for mixtures containing each aminium salt, for example 0.45:1, 0.89:1 and 1.95:1 for MAS.

For sulfate molalities between 0 and $1 \mathrm{~mol} \mathrm{~kg}^{-1}$, osmotic coefficients at all aminium:sulfate ratios fall steeply, as expected, although the larger uncertainties in the osmotic coefficient at these high water activities mask a clear differentiation of the behavior of the solutions at different ratios. At molalities above $1 \mathrm{~mol} \mathrm{~kg}^{-1}$ of sulfate the osmotic coefficients of the solutions for the three aminium:sulfate ratios are quite different, with values in most instances much higher than those of $\left(\mathrm{NH}_{4}\right)_{2} \mathrm{SO}_{4}$ solutions of the same molality. (This corresponds to lower water activities.) The trends are similar for the mixtures for all five aminium salts. Because the aminium:sulfate ratios of the test solutions varied between the different amines studied, more direct comparisons are made with osmotic coefficients determined using the fitted Eq. 3, and are described in the subsections below.

\subsection{Parameterization of the extended ZSR model}

Because all measurements were made at distinct molalities rather than fixed water activity, which is the primary variable in the ZSR model, osmotic coefficients were first calculated at a series of fixed $a_{\mathrm{w}}$ ranging from about 0.4 to 0.975 for each aminium:sulfate ratio. This was done by linearly interpolating the experimental osmotic coefficients (plotted against the square root of sulfate molality). These interpolated values are listed in Table 1 of the Supplementary Information. The results of the interpolations were then fitted to Eq. 3, at each fixed $a_{\mathrm{w}}$ and for the full experimental range of aminium:sulfate ratios, to establish the model parameters for all mixtures. The number of moles of water associated with 1 mole of $\mathrm{H}_{2} \mathrm{SO}_{4}$ at each water activity, which is accurately known, was calculated from the equations of Clegg and Brimblecombe (1995). The unknowns in Eq. 3 are then $w_{\mathrm{as}}{ }^{\mathrm{o}}$, which is the moles of water associated with one mole of the pure aminium salt at each fixed $a_{\mathrm{w}}$, and the mixture parameter $A^{\mathrm{o}}$. Fitted parameters and their uncertainties are listed in Table 2 .

Representative results of the fits of Eq. 3 to the interpolated data are shown in Fig. 2, for a series of water activities from 0.65 to 0.95 . Moving from left to right, the lines on each plot show the transition from pure aqueous $\mathrm{H}_{2} \mathrm{SO}_{4}\left(m_{\text {salt }}=0 \mathrm{~mol} \mathrm{~kg}{ }^{-1}\right)$ to the pure aqueous aminium sulfate salts $\left(m_{\text {acid }}=0 \mathrm{~mol} \mathrm{~kg}^{-1}\right)$. The methylaminium sulfate (MAS, Fig. 2a) and dimethylaminium sulfate (DMAS, Fig. 2b) data are fitted well over the entire composition range, including the solutions with 
compositions very close to pure aminium sulfate. In the case of trimethylaminium sulfate (TMAS, Fig. 2e) there is a suggestion that the model-calculated molalities for the pure aminium sulfate composition are too low (therefore yielding osmotic coefficients that are too high), because of the shape of the fitted curves very close to the x-axis. This may also be true for ethylaminium sulfate (EAS, Fig. 2b) at the lowest $a_{\mathrm{w}}$ fitted, although the results are less clear. In some of the DEAS solutions the amine was in excess, resulting in small negative values of $m_{\text {acid }}$ for two of the solutions shown in Fig. 2d. Calculated water activities for the aqueous $\left(\mathrm{NH}_{4}\right)_{2} \mathrm{SO}_{4}-\mathrm{H}_{2} \mathrm{SO}_{4}$ system are shown in Fig. 2f. For compositions between $\mathrm{NH}_{4} \mathrm{HSO}_{4}$ and $\left(\mathrm{NH}_{4}\right)_{2} \mathrm{SO}_{4}$ the results are clearly very different from those for the aminium-based systems, especially for the pure sulfate salt. This is discussed further below. The fit of Eq. 3 at a single water activity is shown in Fig. 3 for aqueous mixtures of each aminium salt with $\mathrm{H}_{2} \mathrm{SO}_{4}$. The parameter $A^{\mathrm{o}}$ in Eq. 3 accounts for the observed departure from linear behavior (which would yield a straight line between the $\mathrm{kg} \mathrm{H}_{2} \mathrm{O} \mathrm{mol}^{-1}$ values of the two pure solutes).

The results from the fitted Eq. 3 are compared in Fig. 4 with measured and interpolated osmotic coefficients in order to investigate the performance of the model in estimating osmotic coefficients at arbitrary aminium:sulfate ratios. Two aminium:sulfate ratios were initially selected: values close to 2:1 and close to $1: 1$. The results for MAS and DMAS are satisfactory for both ratios, with the fitted Eq. 3 yielding osmotic coefficients that agree with the measurements to within the uncertainty in the model. However, in the cases of EAS (ratio 0.95:1) and TMAS (ratio 1.78:1) there are consistent offsets, with the osmotic coefficients calculated from the measurements lying at the limit of the uncertainty of the model. The same deviations are visible for these ratios in Fig. 2b,e. However, for both salts the deviations of the measured solution molalities from the fitted values, for the nearest ratios to those noted above, lie in the opposite direction. The results for these ratios are shown as osmotic coefficients in Fig. 4f. As expected, the deviations shown in these plots are of opposite sign to those shown in Fig. 4b,e for the closely similar ratios. This confirms they are due to differences in the experimental results, rather than systematic deviations of the model from the data.

For DEAS there are similar consistent differences between measured and fitted osmotic coefficients for the 1.03:1 molar ratio, but there are no data for ratios close to this for comparison. For those DEAS solutions in which the amine was in excess, leading to $m_{\text {acid }}$ values below zero in Fig. $2 \mathrm{~d}$, the water associated with this excess (hence its effect on the molalities $m_{\text {acid }}$ and $m_{\text {salt }}$ ) was estimated by assuming the excess amine takes up water according to Raoult's law, thus

$$
a_{\mathrm{w}}=x \mathrm{H}_{2} \mathrm{O}=n \mathrm{H}_{2} \mathrm{O} /\left(n \mathrm{H}_{2} \mathrm{O}+n \text { Amine }\right)
$$

The total amount of water, for these cases, is therefore assumed to be the sum of the water associated with the pure aminium salt (one of the fitted parameters in Eq. 3) and water associated 
with excess amine for the experimental water activity and obtained using Eq. 6. As shown on Fig. $4 \mathrm{e}$, the treatment of the additional amine in this way yields good agreement with the experimental results.

Overall, the extended ZSR approach embodied in Eq. 3 provides, within the margins of error, good fits to measurements, despite the relatively few data. Nevertheless, there is no reason why the simple model equation should exactly represent the underlying relationship between water activity and composition, complicated as it is by the equilibrium between $\mathrm{H}^{+}, \mathrm{SO}_{4}{ }^{2-}$, and $\mathrm{HSO}_{4}{ }^{-}$ions. Such a difference is apparent in Fig. 2 for aminium:sulfate ratios closest to pure aqueous $\mathrm{H}_{2} \mathrm{SO}_{4}$ : the fitted molalities are greater than those of the test solutions, for all the salts, for water activities of 0.75 and 0.65 . This will result in model-calculated osmotic coefficients that may be too low, which should be borne in mind when using the equations.

\subsection{Comparison of aminium sulfates and bisulfates and their ammonium counterparts} Osmotic coefficients of aqueous aminium bisulfates and sulfates are compared in Fig. 5 to those of their ammonium counterparts (from the work of Clegg et al. [1998], and calculated using the online $E$-AIM model). Within the experimental uncertainty, values for the aqueous aminium bisulfates are in good agreement with ammonium bisulfate, suggesting that at an aminium:sulfate ratio of 1:1 (Fig. 5a) osmotic coefficients of $\mathrm{NH}_{4} \mathrm{HSO}_{4}$ serve as a reasonable proxy for the $\phi_{\text {st }}$ of aqueous aminium bisulfate solutions.

However, as the aminium:sulfate ratio increases from 1:1 to 2:1 (see Fig. 5b), which corresponds to pure aqueous aminium sulfate solutions, the osmotic coefficients increase significantly. There are substantial differences from the osmotic coefficients of ammonium sulfate solutions. These correspond to lower water activities for any given concentration or, conversely, higher water uptake for a given water relative humidity (equilibrium water activity). In contrast, the osmotic coefficients of $\mathrm{NH}_{4} \mathrm{HSO}_{4}$ and $\left(\mathrm{NH}_{4}\right)_{2} \mathrm{SO}_{4}$ solutions exhibit only small differences from each other over the entire concentration range.

Solutions of the primary aminium sulfates (MAS, EAS) have osmotic coefficients closer to ammonium sulfate than the secondary and tertiary aminium compounds (DMAS, DEAS, and TMAS). The relative values of the osmotic coefficients at higher molalities, shown in Fig. 5b, suggest that the numbers of methyl or ethyl groups in the aminium ion may have a stronger effect on water activity than the alkyl chain length has. Similar trends have been observed by Bonner (1981) for methylaminium chloride solutions, where $\left(\mathrm{CH}_{3}\right)_{3} \mathrm{NHCl}$ possesses the largest osmotic coefficients followed by $\left(\mathrm{CH}_{3}\right)_{2} \mathrm{NH}_{2} \mathrm{Cl}$ and $\mathrm{CH}_{3} \mathrm{NH}_{3} \mathrm{Cl}$ at molalities above $4 \mathrm{~mol} \mathrm{~kg}{ }^{-1}$. 
To compare results of this study with those of Clegg et al. (2013) for the aqueous aminium sulfates (their Table 6), we have plotted the moles of water per mole of solute for aqueous MAS, EAS, DMAS, DEAS, and TMAS as a function of equilibrium relative humidity in Fig. 6. Significant differences between all aminium sulfates can be seen (Fig. 6a). However, the results of Clegg et al. (2013), shown in Fig. 6b, correspond quite closely to the properties of aqueous $\left(\mathrm{NH}_{4}\right)_{2} \mathrm{SO}_{4}$ at all relative humidities and are similar to each other. The reason for the differences between the results of the two studies are not known. Clegg et al. (2013) calculated water uptake as a function of relative humidity from size-based hygroscopic growth factors measured by Qiu and Zhang (2012) using an HTDMA, and measured densities of aqueous aminium sulfate solutions. Both the HTDMA experiments and the preparation of the aminium sulfate salts included drying processes down to or below $10 \% R H$, which may have resulted in the evaporation of the amines and a change in the aminium:sulfate ratios, as experienced by Chan and Chan (2013), but this cannot be confirmed. It also seems unlikely that this alone could account for the large differences observed.

Figure $6 \mathrm{c}, \mathrm{d}$ shows plots of the water uptake by aminium nitrate and aminium chloride salts (Bonner 1981; Macaskill and Bates 1986), compared with that of the corresponding ammonium compounds. In both cases the aminium compounds are more hygroscopic than the ammonium salts, thus showing the same qualitative behavior as observed in this study for the sulfates, but to a much smaller degree.

\subsection{Osmotic coefficients of the aminium sulfate salts represented using an ion interaction model}

We have fitted Eq. 4 to stoichiometric osmotic coefficients of the pure aqueous aminium sulfates, from the results listed Table 2, to enable the compounds to be included in models and to extrapolate their properties to higher concentrations than those measured. The value of parameter $V_{\mathrm{w}, \mathrm{Mx}}$ for each salt was constrained so that calculated values of $\phi_{\text {st }}$ values remain above zero to extreme concentration (very low water activity). The model parameters for the five salts are listed in Table 3.

Fitted osmotic coefficients, and the values obtained from the measurements in this study, are shown in Fig. 7. Broadly, the salts with the larger cations (TMAS, DEAS) have the highest osmotic coefficients for any given concentration while aqueous solutions of the salt with the smallest cation (MAS) have osmotic coefficients closest to those of aqueous $\left(\mathrm{NH}_{4}\right)_{2} \mathrm{SO}_{4}$. It should be noted that the parameterization is based on limited data from 1 to $9 \mathrm{~mol} \mathrm{~kg}^{-1}$, hence uncertainties in the parameter values - and especially in the calculated properties beyond the limits of the data - are large. However, the fitted model enables both the easy calculation of osmotic and activity coefficients of aqueous alkylaminium sulfates solutions, and allows them to be included in mixtures (using the same ion interaction model). 


\section{SUMMARY}

In this study water activities of aqueous solutions of five aqueous methyl- and ethyl-aminium sulfates were measured for a range of aminium:sulfate ratios including (close to) bisulfate and sulfate compositions. Volatilization of amine occurred during preparation of bulk solutions but not during the water activity measurements. We demonstrated that measurements on bulk samples, where neither sample preparation nor measurements involve any drying step, is effective in minimizing evaporation and ensuring stable solution compositions during water activity measurements. The use of ion chromatography to determine the cation and anion content of the sample solutions allowed the stoichiometric ratio of aminium to sulfate ions to be verified in the samples.

We used an extended ZSR model to fit the water activity data as a function of composition from pure aqueous $\mathrm{H}_{2} \mathrm{SO}_{4}$ (for which water activities are accurately known) to the pure aqueous aminium sulfates. From the results we obtained estimates of the osmotic coefficients of aqueous solutions of these five salts. At moderate to high concentration the osmotic coefficients are all higher than those of aqueous $\left(\mathrm{NH}_{4}\right)_{2} \mathrm{SO}_{4}$, implying a higher equilibrium water uptake by the aminium sulfates for a given relative humidity. They are thus more hydroscopic than ammonium sulfate, in the order TMAS $>$ DEAS $\approx$ DMAS $>$ EAS $\approx$ MAS $>\left(\mathrm{NH}_{4}\right)_{2} \mathrm{SO}_{4}$. These results differ from those in an earlier study in which water uptake was measured using an HTDMA (Clegg et al. 2013). These differences remain to be resolved.

For mixture compositions of 1:1 aminium:sulfate ratio (i.e., aminium bisulfate) the results of our water activity measurements for all the salts agree, essentially to within experimental uncertainty, with values for $\mathrm{NH}_{4} \mathrm{HSO}_{4}$ at the same solute molality. Hence the use of osmotic coefficients of ammonium bisulfate as estimates of those of methyl- and ethyl-aminium bisulfates is a satisfactory approximation.

\section{ACKNOWLEDGEMENT}

This work was supported by the Research Grants Council of the Hong Kong Special Administrative Region, China (GRF 600112); and by an International Exchange grant from the Royal Society (IE1111149).

\section{REFERENCES}

Almeida, J., Schobesberger, S., Kürten, A., Ortega, I. K., Kupiainen-Maatta, O., Praplan, A. P., 
Adamov, A., Amorim, A., Bianchi, F., Breitenlechner, M., David, A., Dommen, J., Donahue, N. M., Downard, A., Dunne, E., Duplissy, J., Ehrhart, S., Flagan, R. C., Franchin, A., Guida, R., Hakala, J., Hansel, A., Heinritzi, M., Henschel, H., Jokinen, T., Junninen, H., Kajos, M., Kangasluoma, J., Keskinen, H., Kupc, A., Kurten, T., Kvashin, A. N., Laaksonen, A., Lehtipalo, K., Leiminger, M., Leppa, J., Loukonen, V., Makhmutov, V., Mathot, S., McGrath, M. J., Nieminen, T., Olenius, T., Onnela, A., Petaja, T., Riccobono, F., Riipinen, I., Rissanen, M., Rondo, L., Ruuskanen, T., Santos, F. D., Sarnela, N., Schallhart, S., Schnitzhofer, R., Seinfeld, J. H., Simon, M., Sipila, M., Stozhkov, Y., Stratmann, F., Tome, A., Trostl, J., Tsagkogeorgas, G., Vaattovaara, P., Viisanen, Y., Virtanen, A., Vrtala, A., Wagner, P. E., Weingartner, E., Wex, H., Williamson, C., Wimmer, D., Ye, P., Yli-Juuti, T., Carslaw, K. S., Kulmala, M., Curtius, J., Baltensperger, U., Worsnop, D. R., Vehkamaki, H., and Kirkby, J. (2013). Molecular Understanding of Sulphuric Acid-Amine Particle Nucleation in the Atmosphere. Nature 502(7471):359-363.

Blandamer, M. J., Engberts, Jan B. F. N., Gleeson, P. T., and Reis, Joao Carlos R. (2005). Activity of Water in Aqueous Systems; A Frequently Neglected Property. Chem. Soc. Rev. 34(5):440458.

Bonner, O. D. (1981). Osmotic and Activity Coefficients of Methyl-substituted Ammonium Nitrates at 298.15 K. J. Chem. Eng. Data 26(2):148-149.

Bzdek, B. R., Ridge, D. P., and Johnston, M. V. (2010). Amine Exchange into Ammonium Bisulphate and Ammonium Nitrate Nuclei. Atmos. Chem. Phys. 10(8):3495-3503.

Chan, L. P. and Chan, C. K. (2012). Displacement of Ammonium from Aerosol Particles by Uptake of Triethylamine. Aerosol Sci. Technol. 46:236-247.

Chan, L. P. and Chan, C. K. (2013). Role of the Aerosol Phase State in Ammonia/Amines Exchange Reactions. Environ. Sci. Technol. 47(11):5755-5762.

Chang, I.-H., Lee, C.-G., and Lee, D. S. (2003). Development of an Automated Method for Simultaneous Determination of Low Molecular Weight Aliphatic Amines and Ammonia in Ambient Air by Diffusion Scrubber Coupled to Ion Chromatography. Anal. Chem. 75(22):6141-6146.

Clegg, S. L. and Brimblecombe, P. (1995). Application of a Multicomponent Thermodynamic Model to Activities and Thermal Properties of $0-40 \mathrm{~mol} \mathrm{~kg}^{-1}$ Aqueous Sulfuric Acid $328 \mathrm{~K}$ to $<200$ K. J. Chem. Eng. Data 40:43-64.

Clegg, S. L., Brimblecombe, P., and Wexler, A. S. (1998). A Thermodynamic Model of the System $\mathrm{H}^{+}-\mathrm{NH}_{4}{ }^{+}-\mathrm{SO}_{4}{ }^{2-}-\mathrm{NO}_{3}{ }^{-}-\mathrm{H}_{2} \mathrm{O}$ at Tropospheric Temperatures. J. Phys. Chem. A

Clegg, $\dot{S}^{2}$. L., $\bar{H}^{21} 154$ S. S., Chan, C. K., and Brimblecombe, P. (1995). The Thermodynamic Properties of Aqueous $\left(\mathrm{NH}_{4}\right)_{2} \mathrm{SO}_{4}$ to High Supersaturation, as a Function of Temperature. J. Chem. Eng. 
Data 40: 1079-1090.

Clegg, S. L., Pitzer, K. S., and Brimblecombe, P. (1992). Thermodynamics of Multicomponent, Miscible, Ionic Solutions. II. Mixtures Including Unsymmetrical Electrolytes. J. Phys. Chem. 96:9470-9479

Clegg, S. L., Qiu, C., and Zhang, R. (2013). The Deliquescence Behaviour, Solubilities, and Densities of Aqueous Solutions of Five Methyl- and Ethyl-aminium Sulphate Salts. Atmos. Environ. 73:145-158.

Clegg, S. L., Seinfeld, J. H., and Edney, E. O. (2003). Thermodynamic Modelling of Aqueous Aerosols Containing Electrolytes and Dissolved Organic Compounds. II. An Extended ZdanovskiiStokes-Robinson Approach. J. Aerosol Sci. 34(6):667-690.

Fountoukis, C., and Nenes, A. (2007). ISORROPIA II: a Computationally Efficient Thermodynamic Equilibrium Model for $\mathrm{K}^{+}-\mathrm{Ca}^{2+}-\mathrm{Mg}^{2+}-\mathrm{NH}_{4}{ }^{+}-\mathrm{Na}^{+}-\mathrm{SO}_{4}{ }^{2-}-\mathrm{NO}_{3}{ }^{-}-\mathrm{Cl}^{-}-\mathrm{H}_{2} \mathrm{O}$ aerosols. Atmos. Chem. Phys., 7:4639-4659.

Ge, X., Wexler, A. S., and Clegg, S. L. (2011a). Atmospheric Amines - Part I. A Review. Atmos. Environ. 45(3):524-546.

Ge, X., Wexler, A. S., and Clegg, S. L. (2011b). Atmospheric Amines - Part II. Thermodynamic Properties and Gas/Particle Partitioning. Atmos. Environ. 45(3):561-577.

Kurtén, T., Loukonen, V., Vehkamaki, H., and Kulmala, M. (2008). Amines are Likely to Enhance Neutral and Ion-induced Sulfuric Acid-Water Nucleation in the Atmosphere More Effectively than Ammonia. Atmos. Chem. Phys. 8(14):4095-4103.

Lavi, A., Bluvshtein, N., Segre, E., Segev, L., Flores, M., and Rudich, Y. (2013). Thermochemical, Cloud Condensation Nucleation Ability, and Optical Properties of Alkyl Aminium Sulphate Aerosols. J. Phys. Chem. C 117(43):22412-22421.

Liang, Z., and Chan, C. (1997). A Fast Technique for Measuring Water Activity of Atmospheric Aerosols. Aerosol Sci. Technol. 26:255-268.

Lightstone, J. M., Onasch, T. B., Imre, D., and Oatis, S. (2000). Deliquescence, Efflorescence, and Water Activity in Ammonium Nitrate and Mixed Ammonium Nitrate/Succinic Acid Microparticles. J. Phys. Chem. A 104(41):9337-9346.

Liu, Y., Ma, Q., and He, H. (2012). Heterogeneous Uptake of Amines by Citric Acid and Humic Acid. Environ. Sci. Technol. 46(20):11112-11118.

Lloyd, J. A., Heaton, K. J., and Johnston, M. V. (2009). Reactive Uptake of Trimethylamine into Ammonium Nitrate Particles. J. Phys. Chem. A 113(17):4840-4843.

Macaskill, J. B. and Bates, R. G. (1986). Osmotic and Activity Coefficients of Monomethyl-, Dimethyl-, and Trimethylammonium Chlorides at $25^{\circ}$ C. J. Solution Chem. 15(4):323-330. 
Müller, C., Iinuma, Y., Karstensen, J., van Pinxteren, D., Lehmann, S., Gnauk, T., and Herrmann, H. (2009). Seasonal Variation of Aliphatic Amines in Marine Sub-Micrometer Particles at the Cape Verde Islands. Atmos. Chem. Phys. 9(24):9587-9597.

Murphy, S. M., Sorooshian, A., Kroll, J. H., Ng, N. L., Chhabra, P., Tong, C., Surratt, J. D., Knipping, E., Flagan, R. C., and Seinfeld, J. H. (2007). Secondary Aerosol Formation From Atmospheric Reactions of Aliphatic Amines. Atmos. Chem. Phys. 7(9):2313-2337.

Myerson, A.S., Izmailov, A.F., and Na, H.-S. (1996). Thermodynamic Studies of Levitated Microdroplets of Highly Supersaturated Electrolyte Solutions. J. Crystal Growth. 166:981-988.

Nielsen, C. J., Herrmann, H., and Weller, C. (2012). Atmospheric Chemistry and Environmental Impact of The Use of Amines in Carbon Capture and Storage (CCS). Chem. Soc. Rev. 41(19):6684.

Peng, C. and Chan, C. K. (2001). The Water Cycles of Water-Soluble Organic Salts of Atmospheric Importance. Atmos. Environ. 35(7):1183-1192.

Pratt, K. A., Hatch, L. E., and Prather, K. A. (2009). Seasonal Volatility Dependence of Ambient Particle Phase Amines. Environ. Sci. Technol. 43(14):5276-5281.

Qiu, C., Wang, L., Lal, V., Khalizov, A. F., and Zhang, R. (2011). Heterogeneous Reactions of Alkylamines with Ammonium Sulphate and Ammonium Bisulphate. Environ. Sci. Technol. 45(11):4748-4755.

Qiu, C. and Zhang, R. (2012). Physiochemical Properties of Alkylaminium Sulphates: Hygroscopicity, Thermostability, and Density. Environ. Sci. Technol. 46(8):4474-4480.

Rard, J. A., and Platford, R. F. (1991). Experimental Methods: Isopiestic. In Activity Coefficients in Electrolyte Solutions, 2nd Ed., ed. K. S. Pitzer, CRC Press, Boca Raton, p.209-278.

Rehbein, Peter J. G., Jeong, C.-H., McGuire, M. L., Yao, X., Corbin, J. C., and Evans, G. J. (2011). Cloud and Fog Processing Enhanced Gas-to-Particle Partitioning of Trimethylamine. Environ. Sci. Technol. 45(10):4346-4352.

Robinson, R. A. and Stokes, R. H. (1970). Electrolyte Solutions. Butterworth \& Co., 571pp. (Reprinted by Dover Publications, Mineola, New York, in 2002.)

Smith, J. N., Barsanti, K. C., Friedli, H. R., Ehn, M., Kulmala, M., Collins, D. R., Scheckman, J. H., Williams, B. J., and McMurry, P. H. (2010). Observations of Aminium Salts in Atmospheric Nanoparticles and Possible Climatic Implications. Proc. Natl. Acad. Sci. U.S.A. 107(15):66346639.

Stokes, R. H., and Robinson, R. A. (1966). Interactions in Aqueous Nonelectrolyte Solutions. I. Solute-solvent Equilibria. J. Phys. Chem. 70:2126-2130.

VandenBoer, T. C., Petroff, A., Markovic, M. Z., and Murphy, J. G. (2011). Size Distribution of 
Alkyl Amines in Continental Particulate Matter and Their Online Detection in The Gas and Particle Phase. Atmos. Chem. Phys. 11(9):4319-4332.

Wang, L., Lal, V., Khalizov, A. F., and Zhang, R. (2010). Heterogeneous Chemistry of Alkylamines with Sulfuric Acid: Implications for Atmospheric Formation of Alkylaminium Sulphates. Atmos. Environ. 44(7):2461-2465.

Wexler, A. S., and Clegg, S. L. (2002). Atmospheric Aerosol Models for Systems Including The Ions $\mathrm{H}^{+}, \mathrm{NH}_{4}{ }^{+}, \mathrm{Na}^{+}, \mathrm{SO}_{4}{ }^{2-}, \mathrm{NO}_{3}{ }^{-}, \mathrm{Cl}^{-}, \mathrm{Br}^{-}$, and $\mathrm{H}_{2} \mathrm{O}$. J. Geophys. Res.-Atmos. 107: D14, Art. No. 4207. (E-AIM: http://www.aim.env.uea.ac.uk/aim/aim.php)

Zhang, Y., Seigneur, C., Seinfeld, J. H., Clegg, S. L., Jacobson, M., and Binkowski, F. S. (2000). A Comparative Review of Inorganic Aerosol Thermodynamic Equilibrium Modules: Similarities, Differences, and Their Likely Causes. Atmos. Environ. 34:117-137.

Zuend, A., Marcolli, C., Booth, A. M., Lienhard, D. M., Soonsin, V., Krieger, U. K., Topping, D. O., McFiggans, G., Peter, T., and Seinfeld, J. H. (2011). New and Extended Parameterization of The Thermodynamic Model AIOMFAC: Calculation of Activity Coefficients for Organic-Inorganic Mixtures Containing Carboxyl, Hydroxyl, Carbonyl, Ether, Ester, Alkenyl, Alkyl, and Aromatic Functional Groups, Atmos. Chem. Phys., 11: 9155-9206. 


\section{FIGURES}

\section{Figure Captions}

FIGURE 1. Experimentally determined stoichiometric osmotic coefficients $\left(\phi_{\mathrm{st}}\right)$ plotted against the square root of the total sulfate molality $\left(\mathrm{mSO}_{4}{ }^{2-}\right)$, for aqueous mixtures of all five aminium sulfates with $\mathrm{H}_{2} \mathrm{SO}_{4}$, at three different aminium:sulfate molar ratios (noted on the plots). Different symbols are used for each ratio. The solid line shows values for aqueous $\left(\mathrm{NH}_{4}\right)_{2} \mathrm{SO}_{4}$ (Clegg et al. 1995), and the dashed line for aqueous $\mathrm{H}_{2} \mathrm{SO}_{4}(\mathrm{Clegg}$ and Brimblecombe 1995). (a) MAS (methylaminium sulfate). (b) EAS (ethylaminium sulfate). (c) DMAS (dimethylaminium sulfate). (d) DEAS (diethylaminium sulfate). (e) TMAS (trimethylaminium sulfate).

FIGURE 2: Aminium sulfate $\left(m_{\text {salt }}\right)$ and $\mathrm{H}_{2} \mathrm{SO}_{4}$ molalities ( $\left.m_{\text {acid }}\right)$ in the mixtures, interpolated for fixed water activities from 0.65 to 0.95 (indicated on the plots). Symbols: values from Table 1 of the Supplementary Information. Lines: calculated using the fitted extended ZSR model (Eq. 3) using coefficients from Table 2. (a) MAS. (b) EAS. (c) DMAS. (d) DEAS. (e) TMAS. (f) Molalities of aqueous $\left(\mathrm{NH}_{4}\right)_{2} \mathrm{SO}_{4}-\mathrm{H}_{2} \mathrm{SO}_{4}$ mixtures, calculated using the model of Clegg et al. (1998).

FIGURE 3: The mass $(\mathrm{kg})$ of water per mole of total solutes, at a water activity of 0.70 , plotted against the dry mole fraction of aminium sulfate salt present $\left(x_{\text {salt }}\right)$, from pure aqueous $\mathrm{H}_{2} \mathrm{SO}_{4}\left(x_{\text {salt }}=0.0\right)$ to pure aqueous aminium sulfate $\left(x_{\text {salt }}=1.0\right)$. Symbols: open circle - interpolated values from Table 1 of the Supplementary Information; filled circle pure aqueous $\mathrm{H}_{2} \mathrm{SO}_{4}$ from the work of Clegg and Brimblecombe (1995). Lines - calculated using the fitted extended ZSR model (Eq. 3) using coefficients from Table 2. (a) MAS. (b) EAS. (c) DMAS. (d) DEAS. (e) TMAS.

FIGURE 4. Stoichiometric osmotic coefficients $\left(\phi_{\mathrm{st}}\right)$ plotted against the square root of the total sulfate molality $\left(\mathrm{mSO}_{4}{ }^{2-}\right)$, for aqueous mixtures of all five aminium sulfates with $\mathrm{H}_{2} \mathrm{SO}_{4}$, at two different aminium:sulfate molar ratios (noted on the plots). Symbols: solid and shaded - experimental values (Table 1); open symbols - interpolated (Table 1 of the Supplementary Information). Lines: solid - from the fit of the extended ZSR model (Eq. 3), with coefficients listed in Table 2; dashed - these indicate the effects of the uncertainties in the fit of Eq. 3. (a) MAS. (b) EAS. (c) DMAS. (d) DEAS. (e) TMAS. (f) Additional results for EAS and TMAS (as indicated) for ratios close to those shown in plots (b) and (e). 
FIGURE 5. Stoichiometric osmotic coefficients $\left(\phi_{\mathrm{st}}\right)$ of aminium bisulfates (aminium:sulfate ratio 1:1) and aminium sulfates (ratio 2:1) plotted against the square root of total sulfate molality $\left(\mathrm{mSO}_{4}{ }^{2-}\right)$. Symbols: values calculated using the extended ZSR model (Eq. 3), with parameters listed in Table 2. Lines: values for aqueous $\mathrm{NH}_{4} \mathrm{HSO}_{4}$ (plot a) and $\left(\mathrm{NH}_{4}\right)_{2} \mathrm{SO}_{4}$ (plot b) calculated from the results of Clegg et al. (1998), and Clegg et al. (1995), respectively. The identities of the aminium salts in the mixtures are indicated on the plots. (a) Aqueous aminium bisulfates, and $\mathrm{NH}_{4} \mathrm{HSO}_{4}$. For clarity, the results for sulfates EAS to TMAS are offset vertically by the amounts indicated in parentheses on the plot. (b) Aqueous aminium sulfates, and $\left(\mathrm{NH}_{4}\right)_{2} \mathrm{SO}_{4}$.

FIGURE 6. Comparison of water uptake by different aminium salts plotted as moles of water $\left(n \mathrm{H}_{2} \mathrm{O}\right)$ per mole of salt against equilibrium relative humidity $(R H$, as a fraction). Symbols: circle - methylaminium; solid circle - ethylaminium; square - dimethylaminium; solid square - diethylaminium; triangle - trimethylaminium. (a) Sulfates (this study). Values for the points were calculated using the extended ZSR model (Eq. 3), with coefficients in Table 2. The lowest line on the plot is for aqueous $\left(\mathrm{NH}_{4}\right)_{2} \mathrm{SO}_{4}$ and was calculated using the results of Clegg et al. (1995). Other lines, for each aminium sulfate, were calculated using Eq. 4 and the parameters in Table 3. (b) Sulfates (Clegg et al. 2013). The values for the points were taken from their Table 6. The line is for aqueous $\left(\mathrm{NH}_{4}\right)_{2} \mathrm{SO}_{4}$, the same as in (a). (c) Nitrates (Bonner 1981). The line is for aqueous $\mathrm{NH}_{4} \mathrm{NO}_{3}$, calculated using the results of Clegg et al. (1998). (d) Chlorides (Macaskill and Bates 1986). The line is for aqueous $\mathrm{NH}_{4} \mathrm{Cl}$, calculated using the equation of Liang and Chan (1997) and results of Myerson et al. (1996).

FIGURE 7. Stoichiometric osmotic coefficients $\left(\phi_{\mathrm{st}}\right)$ of the aminium sulfates, plotted against the square root of sulfate molality $\left(\mathrm{mSO}_{4}{ }^{2-}\right)$. Symbols: osmotic coefficients of each salt (as indicated on the plot) calculated using Eq. 3 with the coefficients in Table 2. Lines: osmotic coefficients fitted using the ion interaction model (Eq. 4), and calculated using the parameters in Table 3 . 
FIGURE 1:
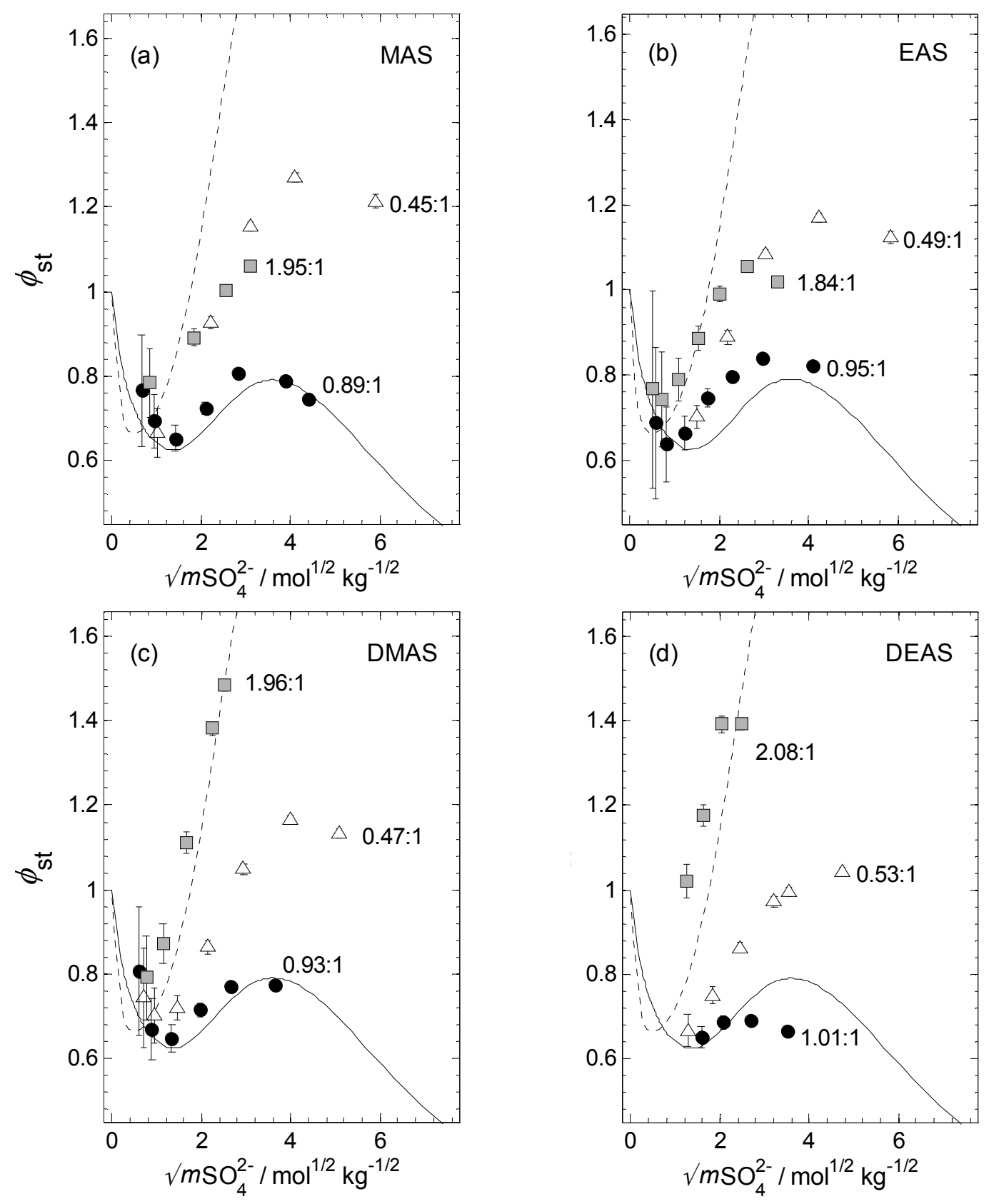

50

51

52

53

54

55

56

57

58

59

60

Editorial Office phone: 612-827-2421 http://mc.manuscriptcentral.com/ast 
1

2

3

4

5

6

7

8

9

10

11

12

13

14

15

16

17

18

19

20

21

22

23

24

25

26

27

28

29

30

31

32

33

34

35

36

37

38

39

40

41

42

43

44

45

46

47

48

49

50

51

52

53

54

55

56

57

58

59

60

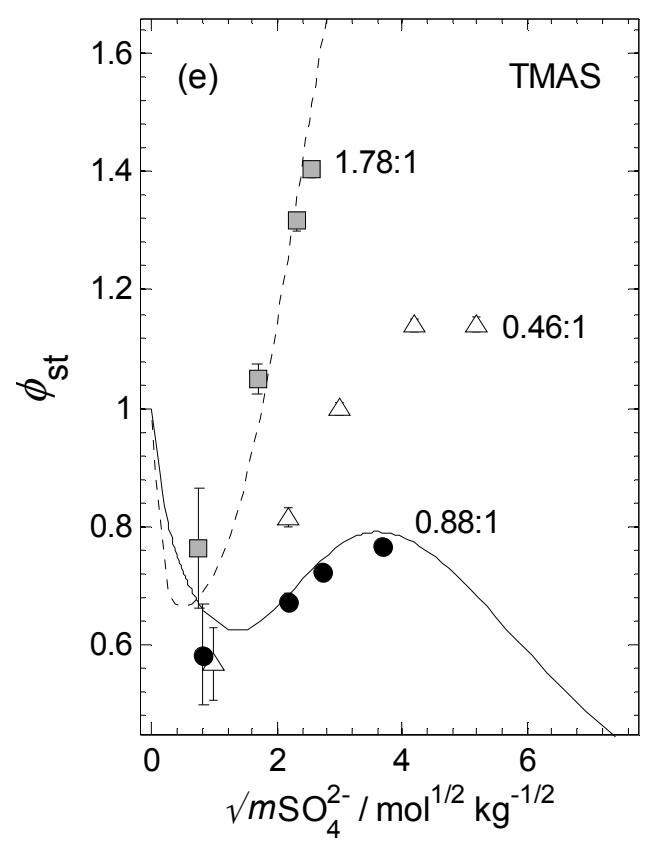

Editorial Office phone: 612-827-2421 http://mc.manuscriptcentral.com/ast 
FIGURE 2:
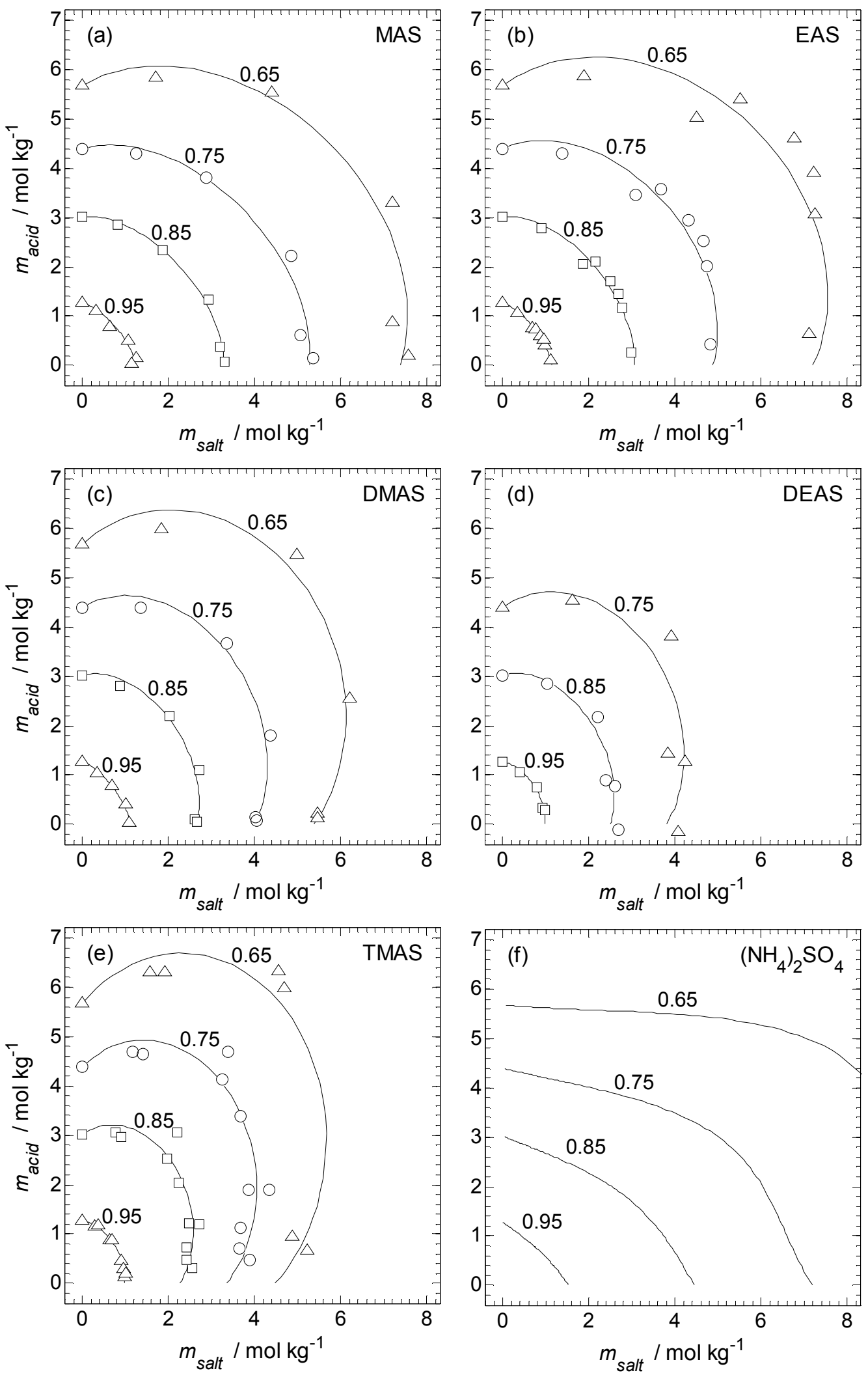

Editorial Office phone: 612-827-2421 http://mc.manuscriptcentral.com/ast 
FIGURE 3:
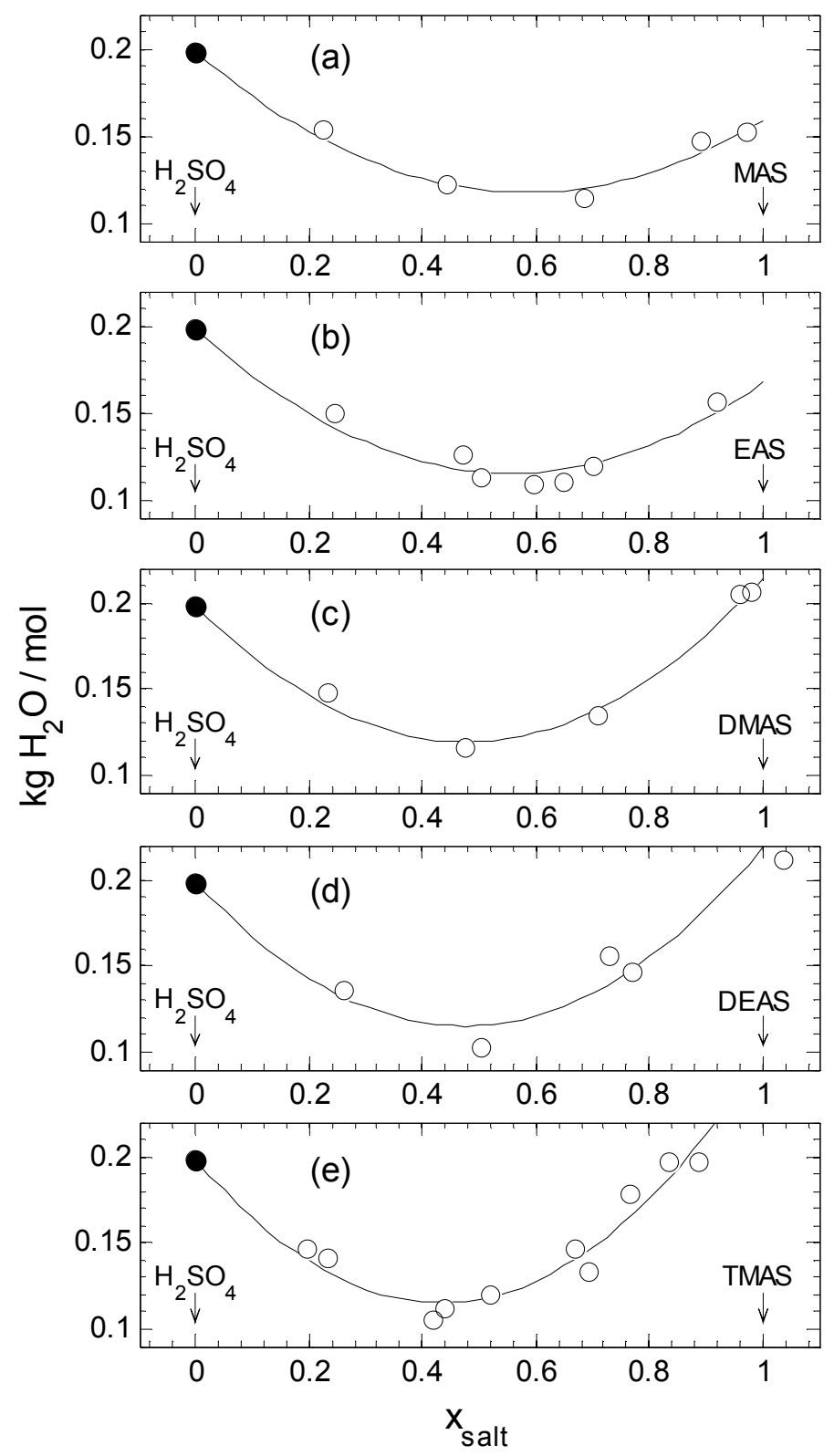

44
45

46

47

48

49

50

51

52

53

54

55

56

57

58

59

60 
FIGURE 4:
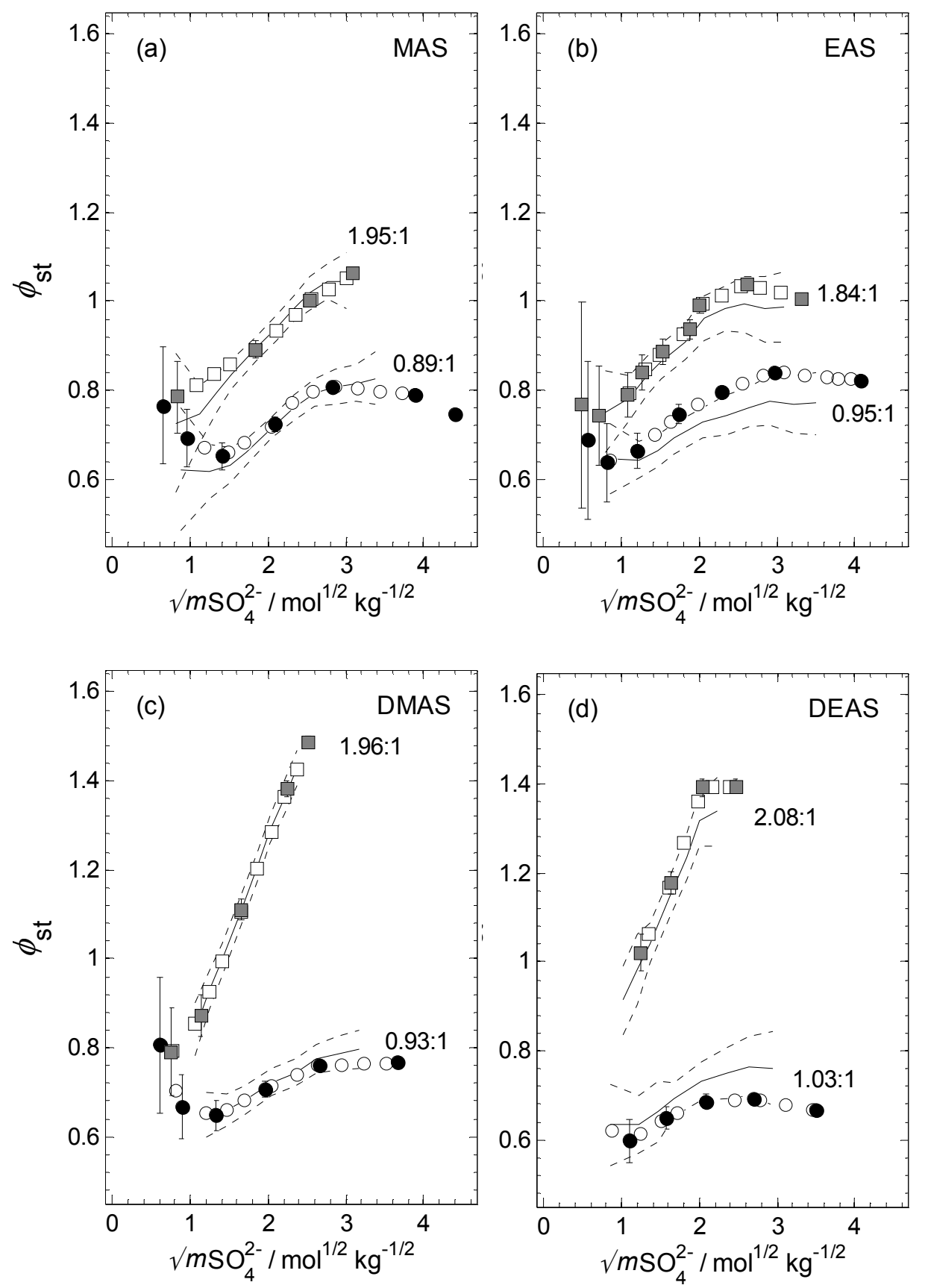

47

48

49

50

51

52

53

54

55

56

57

58

59

60

Editorial Office phone: 612-827-2421 http://mc.manuscriptcentral.com/ast 


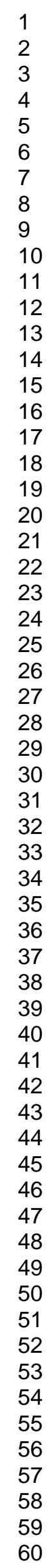
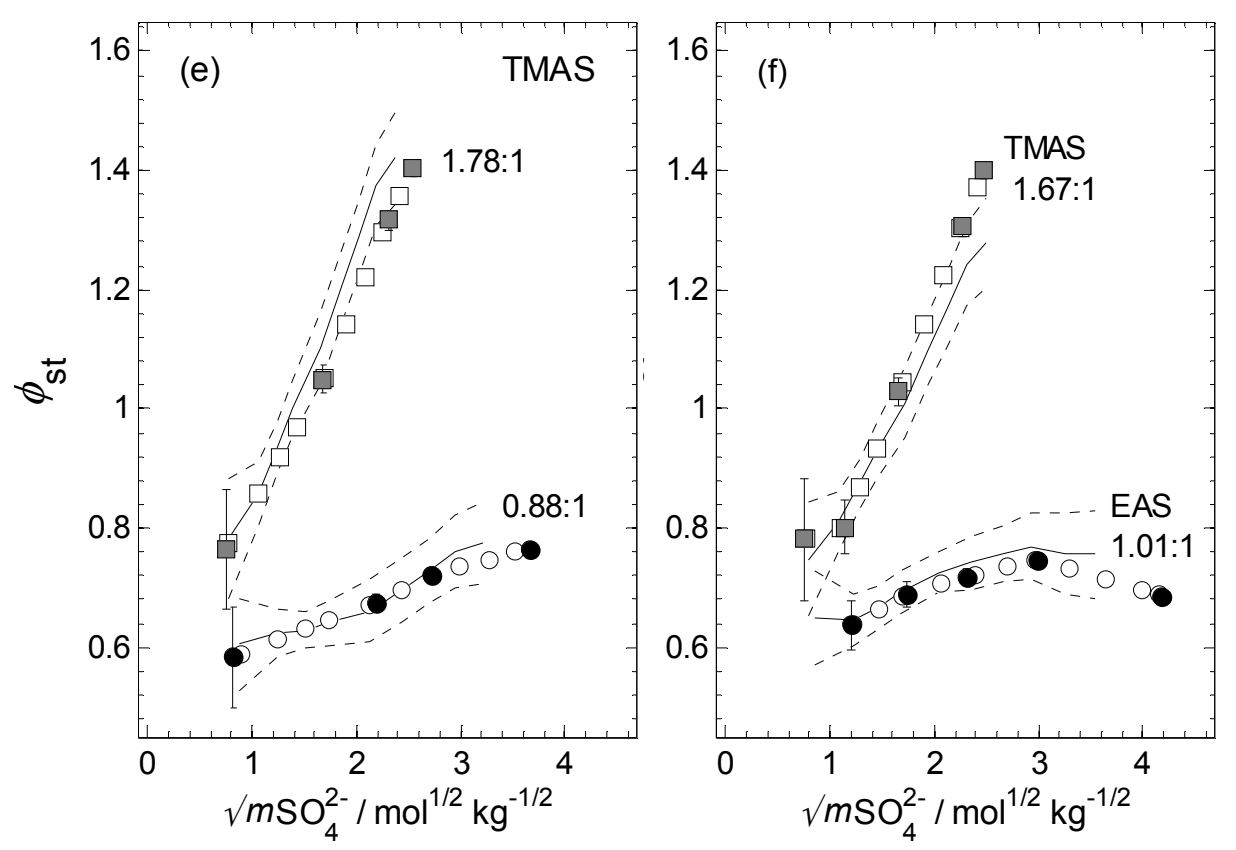

30

31

33

34

35

36

37

38

40

41

42

43

45

46

47

48

50

51

52

53

54

56

57

58

59

Editorial Office phone: 612-827-2421 http://mc.manuscriptcentral.com/ast 
FIGURE 5:
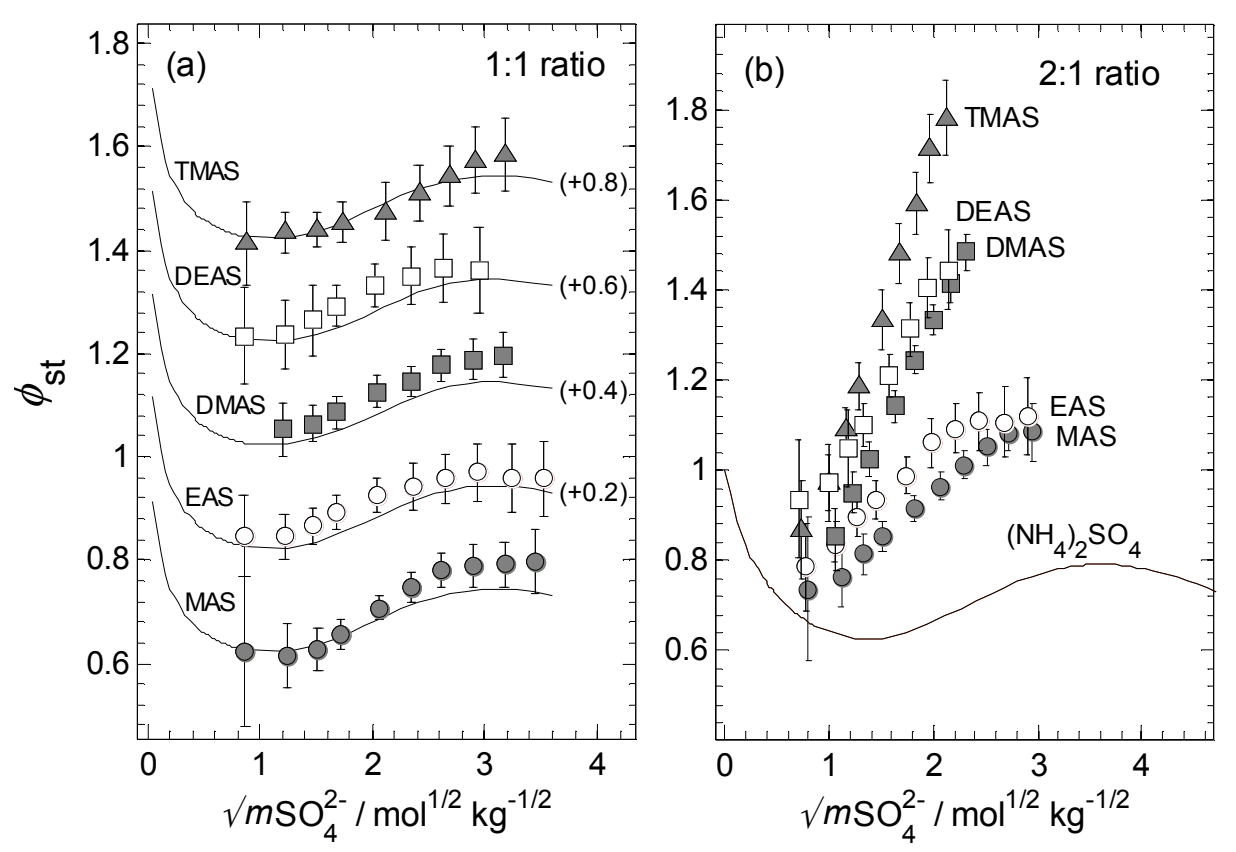

27

28

29

30

31

32

33

34

35

36

37

38

39

40

41

42

43

44

45

46

47

48

49

50

51

52

53

54

55

56

57

58

59

60

Editorial Office phone: 612-827-2421 http://mc.manuscriptcentral.com/ast 
FIGURE 6:
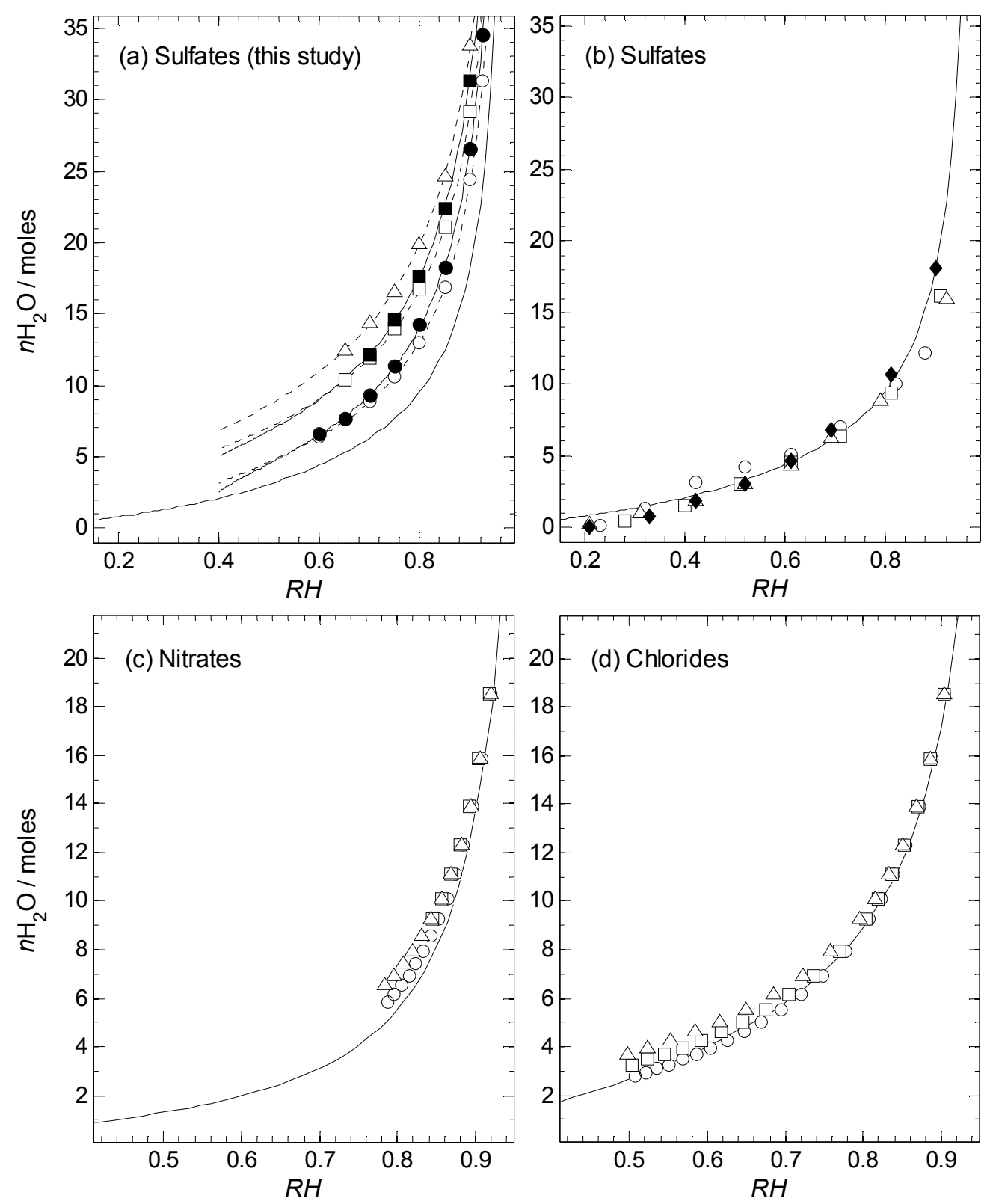

44

46

47

48

49

50

51

52

53

54

55

56

57

58

59

60

Editorial Office phone: 612-827-2421 http://mc.manuscriptcentral.com/ast 
FIGURE 7:

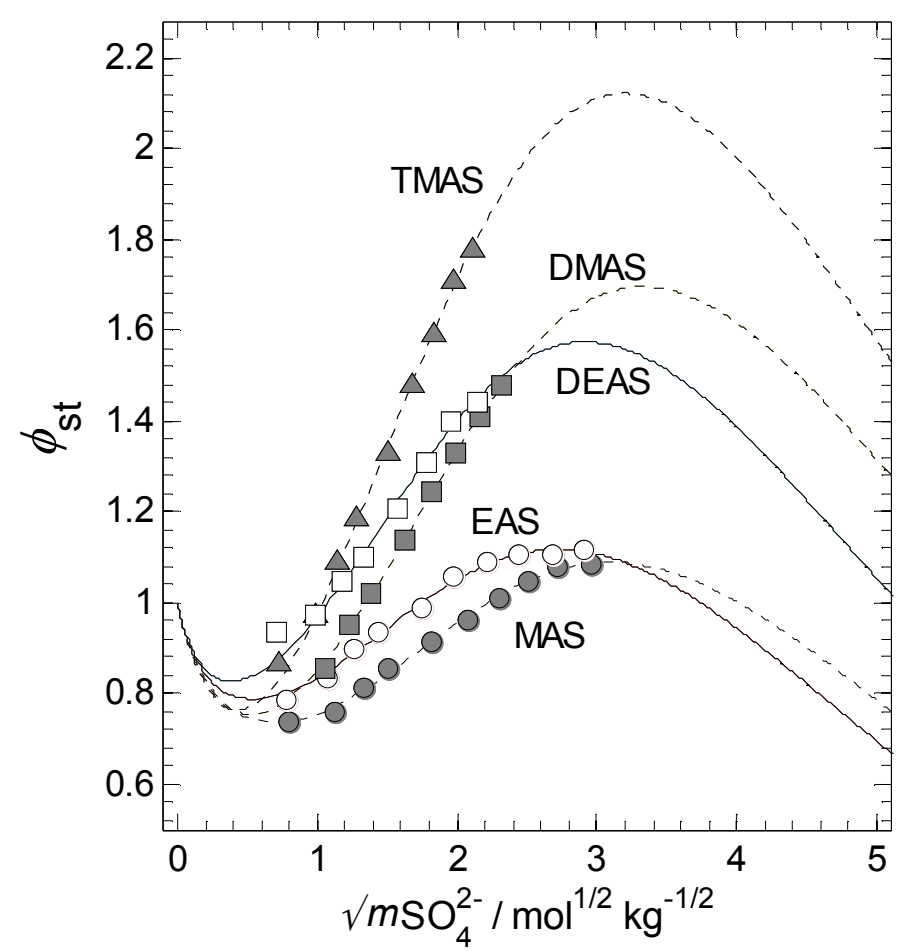

29
30

31

32

33

34

35

36

37

38

39

40

41

42

43

44

45

46

47

48

49

50

51

52

53

54

55

56

57

58

59

60 


\section{TABLES}

TABLE 1. Experimental Values of Water Activities $\left(a_{\mathrm{w}}\right)$ and Calculated Stoichiometric Osmotic Coefficients $\left(\phi_{\mathrm{st}}\right)$ of Aminium Sulfate $-\mathrm{H}_{2} \mathrm{SO}_{4}$ Solutions at $25.0 \pm 0.2^{\circ} \mathrm{C}$. $^{a}$

\begin{tabular}{|c|c|c|c|c|}
\hline \multicolumn{2}{|c|}{ aminium:sulfate ratio ${ }^{b}$} & \multirow{2}{*}{$\frac{a_{\mathrm{w}}}{0.996}$} & \multirow{2}{*}{$\frac{m \mathrm{SO}_{4}{ }^{2-}\left(\mathrm{mol} \mathrm{kg}^{-1}\right)^{c}}{0.0513 \pm 0.0013}$} & \multirow{2}{*}{$\frac{\phi_{\mathrm{st}}}{(1.5664 \pm 1.0878)}$} \\
\hline MAS & $0.4461 \pm 0.0150$ & & & \\
\hline & $0.4461 \pm 0.0150$ & 0.987 & $0.4873 \pm 0.0119$ & $0.4968 \pm 0.1157$ \\
\hline & $0.4461 \pm 0.0150$ & 0.968 & $1.0204 \pm 0.0249$ & $0.5898 \pm 0.0566$ \\
\hline & $0.4518 \pm 0.0120$ & 0.964 & $1.0191 \pm 0.0206$ & $0.6657 \pm 0.0568$ \\
\hline & $0.4461 \pm 0.0150$ & 0.919 & $2.2869 \pm 0.0558$ & $0.6864 \pm 0.0269$ \\
\hline & $0.4461 \pm 0.0150$ & 0.783 & $4.9235 \pm 0.1202$ & $0.9209 \pm 0.0150$ \\
\hline & $0.4518 \pm 0.0120$ & 0.781 & $4.9268 \pm 0.0997$ & $0.9267 \pm 0.0148$ \\
\hline & $0.4461 \pm 0.0150$ & 0.555 & $9.5249 \pm 0.2325$ & $1.1438 \pm 0.0113$ \\
\hline & $0.4518 \pm 0.0120$ & 0.551 & $9.5332 \pm 0.1929$ & $1.1556 \pm 0.0110$ \\
\hline & $0.4461 \pm 0.0150$ & 0.325 & $16.828 \pm 0.4107$ & $1.2358 \pm 0.0110$ \\
\hline & $0.4518 \pm 0.0120$ & 0.314 & $16.872 \pm 0.3413$ & $1.2692 \pm 0.0110$ \\
\hline & $0.4461 \pm 0.0150$ & 0.106 & $34.737 \pm 0.5789$ & $1.1954 \pm 0.0153$ \\
\hline & 20 & 0.1 & 34.9 & $1.2144 \pm 0$. \\
\hline & $1 \pm 0.0200$ & 0.993 & 0010 & $(2.9913 \pm$ \\
\hline & $0.8851 \pm 0.0200$ & 0.982 & $0.4307 \pm 0.0101$ & $0.7658 \pm 0.1315$ \\
\hline & $0.8610 \pm 0.0110$ & 0.968 & $0.8832 \pm 0.0142$ & $0.6886 \pm 0.0651$ \\
\hline & $0.8851 \pm 0.0200$ & 0.967 & $0.8961 \pm 0.0$ & $0.6929 \pm 0.0643$ \\
\hline & $0.8851 \pm 0.0200$ & 0.933 & $1.9796 \pm 0.0464$ & $0.6516 \pm 0.0303$ \\
\hline & $0.8851 \pm 0.0200$ & 0.843 & $4.3775 \pm 0.1025$ & $0.7236 \pm 0.0153$ \\
\hline & $0.8610 \pm 0.0110$ & 0.840 & $4.3006 \pm 0.0692$ & $0.7501 \pm 0.0155$ \\
\hline & $0.8610 \pm 0.0110$ & 0.708 & $7.8069 \pm 0.1256$ & $0.8184 \pm 0.0102$ \\
\hline & $0.8851 \pm 0.0200$ & 0.705 & $8.0047 \pm 0.1875$ & $0.8080 \pm 0.0101$ \\
\hline & $0.8851 \pm 0.0200$ & 0.524 & $15.143 \pm 0.3546$ & $0.7897 \pm 0.0073$ \\
\hline & $0.8610 \pm 0.0110$ & 0.522 & $14.542 \pm 0.2339$ & $0.8264 \pm 0.0074$ \\
\hline & $0.8851 \pm 0.0200$ & 0.457 & $19.419 \pm 0.2413$ & $0.7454 \pm 0.0064$ \\
\hline & $0.8610 \pm 0.0110$ & 0.448 & $18.539 \pm 0.1247$ & $0.8014 \pm 0.0067$ \\
\hline & $1.3528 \pm 0.0410$ & 0.995 & $0.0359 \pm 0.0010$ & $(2.7555 \pm 1.5556)$ \\
\hline & $1.3528 \pm 0.0410$ & 0.993 & $0.1813 \pm 0.0052$ & $0.7169 \pm 0.3087$ \\
\hline & $1.3528 \pm 0.0410$ & 0.988 & $0.3765 \pm 0.0108$ & $0.5767 \pm 0.1495$ \\
\hline & $1.3708 \pm 0.0410$ & 0.973 & $0.7800 \pm 0.0224$ & $0.6534 \pm 0.0735$ \\
\hline & $1.3528 \pm 0.0410$ & 0.946 & $1.7189 \pm 0.0494$ & $0.6014 \pm 0.0345$ \\
\hline & $1.3708 \pm 0.0410$ & 0.872 & $3.6827 \pm 0.1056$ & $0.6910 \pm 0.0177$ \\
\hline & $1.3708 \pm 0.0410$ & 0.758 & $6.8136 \pm 0.1950$ & $0.7512 \pm 0.0112$ \\
\hline
\end{tabular}


$1.3708 \pm 0.0410 \quad 0.613 \quad 11.893 \pm 0.1768$

$0.7627 \pm 0.0080$

$1.7819 \pm 0.0510 \quad 0.999 \quad 0.0314 \pm 0.0009$

$(0.3924 \pm 1.7667)$

$1.7819 \pm 0.0510 \quad 0.994 \quad 0.1235 \pm 0.0036$

$0.9015 \pm 0.4527$

$1.7819 \pm 0.0510 \quad 0.989 \quad 0.3452 \pm 0.0101$

$0.6110 \pm 0.1631$

$1.7819 \pm 0.0510 \quad 0.974 \quad 0.7029 \pm 0.0206$

$0.6844 \pm 0.0815$

$1.7819 \pm 0.0510 \quad 0.944 \quad 1.5640 \pm 0.0459$

$0.6818 \pm 0.0381$

$1.7819 \pm 0.0510 \quad 0.862 \quad 3.3066 \pm 0.0971$

$0.8288 \pm 0.0200$

$1.7819 \pm 0.0510 \quad 0.723 \quad 6.2423 \pm 0.1833$

$0.9600 \pm 0.0130$

$1.7819 \pm 0.0510 \quad 0.612 \quad 9.0849 \pm 0.1316$

$0.9989 \pm 0.0107$

$1.9486 \pm 0.0160 \quad 0.971 \quad 0.7021 \pm 0.0106$

$0.7846 \pm 0.0816$

$1.9486 \pm 0.0160 \quad 0.850 \quad 3.3675 \pm 0.0510$

$0.8908 \pm 0.0195$

$\begin{array}{llll}1.9486 \pm 0.0160 & 0.705 & 6.4547 \pm 0.0978\end{array}$

$1.0007 \pm 0.0123$

$\begin{array}{llll}1.9486 & \pm 0.0160 & 0.579 & 9.5286 \pm 0.0496\end{array}$

$1.0611 \pm 0.0101$

\begin{tabular}{ccccc}
\hline \multicolumn{2}{c}{ aminium:sulfate ratio } & $a_{\mathrm{w}}$ & $\mathrm{mSO}_{4}{ }^{2-}\left(\mathrm{mol} \mathrm{kg}^{-1}\right)^{c}$ & $\phi_{\mathrm{st}}$ \\
\hline EAS & $0.4825 \pm 0.0200$ & 0.993 & $0.0524 \pm 0.0020$ & $(2.3623 \pm 1.0694)$ \\
$0.4825 \pm 0.0200$ & 0.983 & $0.4729 \pm 0.0183$ & $0.6576 \pm 0.1201$ \\
$0.4825 \pm 0.0200$ & 0.967 & $0.9528 \pm 0.0368$ & $0.6517 \pm 0.0610$ \\
$0.4870 \pm 0.0230$ & 0.919 & $2.2161 \pm 0.1004$ & $0.7052 \pm 0.0282$ \\
$0.4914 \pm 0.0230$ & 0.794 & $4.7903 \pm 0.2161$ & $0.8894 \pm 0.0160$ \\
$0.4825 \pm 0.0200$ & 0.794 & $4.7872 \pm 0.1851$ & $0.8932 \pm 0.0157$ \\
$0.4914 \pm 0.0230$ & 0.586 & $9.1326 \pm 0.4120$ & $1.0839 \pm 0.0121$ \\
$0.4825 \pm 0.0200$ & 0.488 & $9.1332 \pm 0.3532$ & $(1.4535 \pm 0.0142)$ \\
$0.4870 \pm 0.0230$ & 0.321 & $17.749 \pm 0.8044$ & $1.1863 \pm 0.0115$ \\
$0.4870 \pm 0.0230$ & 0.124 & $33.931 \pm 1.2267$ & $1.1393 \pm 0.0144$ \\
$0.9454 \pm 0.0360$ & 0.998 & $0.0303 \pm 0.0012$ & $(1.4288 \pm 1.8405)$ \\
$0.9454 \pm 0.0360$ & 0.988 & $0.3158 \pm 0.0123$ & $0.6875 \pm 0.1785$ \\
$0.9454 \pm 0.0360$ & 0.978 & $0.6555 \pm 0.0255$ & $0.6375 \pm 0.0872$ \\
$0.9454 \pm 0.0360$ & 0.949 & $1.4590 \pm 0.0569$ & $0.6638 \pm 0.0407$ \\
$0.9454 \pm 0.0360$ & 0.886 & $2.9979 \pm 0.1168$ & $0.7447 \pm 0.0216$ \\
$0.9454 \pm 0.0360$ & 0.798 & $5.2503 \pm 0.2046$ & $0.7952 \pm 0.0140$ \\
$0.9454 \pm 0.0360$ & 0.671 & $8.7775 \pm 0.3420$ & $0.8411 \pm 0.0102$ \\
$0.9454 \pm 0.0360$ & 0.478 & $16.607 \pm 0.4429$ & $0.8224 \pm 0.0074$ \\
$1.0099 \pm 0.0500$ & 0.951 & $1.4569 \pm 0.0760$ & $0.6381 \pm 0.0411$ \\
$1.0099 \pm 0.0500$ & 0.893 & $3.0307 \pm 0.1582$ & $0.6886 \pm 0.0216$ \\
$1.0099 \pm 0.0500$ & 0.813 & $5.3265 \pm 0.2780$ & $0.7192 \pm 0.0139$ \\
$1.0099 \pm 0.0500$ & 0.697 & $8.9513 \pm 0.4672$ & $0.7471 \pm 0.0101$
\end{tabular}

Editorial Office phone: 612-827-2421 http://mc.manuscriptcentral.com/ast 


\begin{tabular}{llll}
$1.0099 \pm 0.0500$ & 0.524 & $17.406 \pm 0.6802$ & $0.6870 \pm 0.0068$ \\
$1.1905 \pm 0.0200$ & 0.971 & $0.7913 \pm 0.0218$ & $0.6881 \pm 0.0725$ \\
$1.1905 \pm 0.0200$ & 0.939 & $1.8068 \pm 0.0498$ & $0.6446 \pm 0.0330$ \\
$1.1905 \pm 0.0200$ & 0.856 & $4.0262 \pm 0.1111$ & $0.7128 \pm 0.0164$ \\
$1.1905 \pm 0.0200$ & 0.736 & $7.7104 \pm 0.2127$ & $0.7356 \pm 0.0100$ \\
$1.1905 \pm 0.0200$ & 0.568 & $15.745 \pm 0.2299$ & $0.6654 \pm 0.0063$ \\
$1.2978 \pm 0.0370$ & 0.956 & $1.2983 \pm 0.0548$ & $0.6413 \pm 0.0453$ \\
$1.2978 \pm 0.0370$ & 0.903 & $2.6853 \pm 0.1133$ & $0.7056 \pm 0.0235$ \\
$1.2978 \pm 0.0370$ & 0.831 & $4.6696 \pm 0.1970$ & $0.7351 \pm 0.0150$ \\
$1.2978 \pm 0.0370$ & 0.732 & $7.7931 \pm 0.3287$ & $0.7418 \pm 0.0104$ \\
$1.2978 \pm 0.0370$ & 0.601 & $13.389 \pm 0.2982$ & $0.7029 \pm 0.0072$ \\
$1.4046 \pm 0.0390$ & 0.995 & $0.0304 \pm 0.0011$ & $(2.8436 \pm 1.8344)$ \\
$1.4046 \pm 0.0390$ & 0.987 & $0.2846 \pm 0.0105$ & $0.8287 \pm 0.1981$ \\
$1.4046 \pm 0.0390$ & 0.979 & $0.5875 \pm 0.0216$ & $0.6792 \pm 0.0970$ \\
$1.4046 \pm 0.0390$ & 0.954 & $1.2774 \pm 0.0469$ & $0.6770 \pm 0.0460$ \\
$1.4046 \pm 0.0390$ & 0.901 & $2.6358 \pm 0.0968$ & $0.7292 \pm 0.0239$ \\
$1.4046 \pm 0.0390$ & 0.824 & $4.6022 \pm 0.1690$ & $0.7799 \pm 0.0152$ \\
$1.4046 \pm 0.0390$ & 0.722 & $7.6359 \pm 0.2805$ & $0.7904 \pm 0.0106$ \\
$1.4046 \pm 0.0390$ & 0.581 & $13.253 \pm 0.3098$ & $0.7573 \pm 0.0075$ \\
$1.8372 \pm 0.0610$ & 0.997 & $0.0284 \pm 0.0013$ & $(1.7369 \pm 1.9591)$ \\
$1.8372 \pm 0.0610$ & 0.990 & $0.2425 \pm 0.0112$ & $0.7667 \pm 0.2323$ \\
$1.8379 \pm 0.0760$ & 0.985 & $0.3304 \pm 0.0183$ & $(0.8465 \pm 0.1724)$ \\
$1.8372 \pm 0.0610$ & 0.980 & $0.5109 \pm 0.0235$ & $0.7439 \pm 0.1120$ \\
$1.8372 \pm 0.0610$ & 0.951 & $1.1781 \pm 0.0542$ & $0.7891 \pm 0.0507$ \\
$1.8379 \pm 0.0760$ & 0.931 & $1.5822 \pm 0.0875$ & $0.8403 \pm 0.0395$ \\
$1.8372 \pm 0.0610$ & 0.894 & $2.3370 \pm 0.1076$ & $0.8872 \pm 0.0279$ \\
$1.8379 \pm 0.0760$ & 0.837 & $3.5098 \pm 0.1940$ & $0.9359 \pm 0.0209$ \\
$1.8372 \pm 0.0610$ & 0.805 & $4.0464 \pm 0.1863$ & $0.9919 \pm 0.0185$ \\
$1.8376 \pm 0.0760$ & 0.680 & $6.8598 \pm 0.3818$ & $1.0391 \pm 0.0140$ \\
$1.8376 \pm 0.0760$ & 0.551 & $10.962 \pm 0.4204$ & $1.0057 \pm 0.0104$ \\
\hline & & &
\end{tabular}

\begin{tabular}{|c|c|c|c|c|}
\hline $\operatorname{amin}$ & nium:sulfate ratio ${ }^{b}$ & $a_{\mathrm{w}}$ & $m \mathrm{SO}_{4}{ }^{2-}\left(\mathrm{mol} \mathrm{kg}^{-1}\right)^{c}$ & $\phi_{\text {st }}$ \\
\hline \multirow[t]{5}{*}{ DMAS } & $0.4729 \pm 0.0180$ & 0.991 & $0.0489 \pm 0.0016$ & $(3.5509 \pm 1.1500)$ \\
\hline & $0.4729 \pm 0.0180$ & 0.981 & $0.4851 \pm 0.0154$ & $(0.7447 \pm 0.1174)$ \\
\hline & $0.4692 \pm 0.0180$ & 0.968 & $0.8855 \pm 0.0281$ & $0.6761 \pm 0.0655$ \\
\hline & $0.4729 \pm 0.0180$ & 0.920 & $2.1384 \pm 0.0679$ & $0.7183 \pm 0.0289$ \\
\hline & $0.4692 \pm 0.0180$ & 0.805 & $4.6242 \pm 0.1466$ & $0.8671 \pm 0.0157$ \\
\hline
\end{tabular}




$\begin{array}{lllc}0.4692 \pm 0.0180 & 0.611 & 8.6305 \pm 0.2743 & 1.0562 \pm 0.0115 \\ 0.4692 \pm 0.0180 & 0.363 & 15.875 \pm 0.5061 & 1.1812 \pm 0.0107 \\ 0.4692 \pm 0.0180 & 0.198 & 25.817 \pm 0.5320 & 1.1599 \pm 0.0118 \\ 0.9341 \pm 0.0250 & 0.992 & 0.0427 \pm 0.0013 & (3.4774 \pm 1.3112) \\ 0.9341 \pm 0.0250 & 0.984 & 0.3699 \pm 0.0112 & 0.8067 \pm 0.1529 \\ 0.9541 \pm 0.0250 & 0.972 & 0.7873 \pm 0.0238 & 0.6674 \pm 0.0730 \\ 0.9341 \pm 0.0250 & 0.940 & 1.7776 \pm 0.0537 & 0.6477 \pm 0.0336 \\ 0.9541 \pm 0.0250 & 0.863 & 3.8492 \pm 0.1158 & 0.7065 \pm 0.0172 \\ 0.9541 \pm 0.0250 & 0.747 & 7.0988 \pm 0.2132 & 0.7604 \pm 0.0110 \\ 0.9541 \pm 0.0250 & 0.572 & 13.475 \pm 0.2024 & 0.7671 \pm 0.0075 \\ 1.4150 \pm 0.0470 & 0.996 & 0.0357 \pm 0.0013 & (2.2529 \pm 1.5649) \\ 1.4150 \pm 0.0470 & 0.992 & 0.1580 \pm 0.0057 & (0.9408 \pm 0.3550) \\ 1.4150 \pm 0.0470 & 0.985 & 0.3256 \pm 0.0118 & (0.8588 \pm 0.1738 \\ 1.4150 \pm 0.0470 & 0.976 & 0.6847 \pm 0.0249 & 0.6565 \pm 0.0836 \\ 1.4176 \pm 0.0450 & 0.974 & 0.6857 \pm 0.0241 & (0.7016 \pm 0.0836) \\ 1.4150 \pm 0.0470 & 0.946 & 1.5354 \pm 0.0558 & 0.6732 \pm 0.0388 \\ 1.4163 \pm 0.0470 & 0.872 & 3.2931 \pm 0.1198 & 0.7707 \pm 0.0200 \\ 1.4163 \pm 0.0470 & 0.752 & 6.1320 \pm 0.2226 & 0.8621 \pm 0.0128 \\ 1.4163 \pm 0.0470 & 0.634 & 9.1957 \pm 0.1801 & 0.9155 \pm 0.0101 \\ 1.9247 \pm 0.0550 & 0.989 & 0.1369 \pm 0.0046 & (1.4946 \pm 0.4113) \\ 1.9247 \pm 0.0550 & 0.987 & 0.2744 \pm 0.0092 & (0.9052 \pm 0.2059) \\ 1.9247 \pm 0.0550 & 0.971 & 0.5796 \pm 0.0195 & (0.9394 \pm 0.0995) \\ 1.9247 \pm 0.0550 & 0.940 & 1.2923 \pm 0.0434 & 0.8859 \pm 0.0465 \\ 1.9247 \pm 0.0550 & 0.846 & 2.7676 \pm 0.0930 & 1.1154 \pm 0.0247 \\ 1.9247 \pm 0.0550 & 0.690 & 5.0326 \pm 0.1690 & 1.3625 \pm 0.0172 \\ 1.9247 \pm 0.0550 & 0.610 & 6.3280 \pm 0.0998 & 1.4437 \pm 0.0150 \\ 1.9579 \pm 0.0310 & 0.976 & 0.5762 \pm 0.0133 & 0.7910 \pm 0.0990 \\ 1.9579 \pm 0.0310 & 0.941 & 1.2891 \pm 0.0298 & 0.8728 \pm 0.0461 \\ 1.9579 \pm 0.0310 & 0.848 & 2.7407 \pm 0.0634 & 1.1105 \pm 0.0243 \\ 1.9579 \pm 0.0310 & 0.687 & 5.0320 \pm 0.1163 & 1.3822 \pm 0.0166 \\ 1.9579 \pm 0.0310 & 0.601 & 6.3431 \pm 0.0566 & 1.4852 \pm 0.0148 \\ 2.0515 \pm 0.0760 & 0.973 & 0.5809 \pm 0.0245 & (0.8718 \pm 0.0997) \\ 2.0515 \pm 0.0760 & 0.857 & 2.8200 \pm 0.1188 & (1.0125 \pm 0.0247) \\ 2.0515 \pm 0.0760 & 0.723 & 5.2094 \pm 0.2195 & (1.1520 \pm 0.0167) \\ 2.0515 \pm 0.0760 & 0.652 & 6.5885 \pm 0.1485 & (1.2012 \pm 0.0140) \\ & & \end{array}$




\begin{tabular}{|c|c|c|c|c|}
\hline ami & hium:sulfate ratio ${ }^{b}$ & $a_{\mathrm{w}}$ & $m \mathrm{SO}_{4}{ }^{2-}\left(\mathrm{mol} \mathrm{kg}^{-1}\right)^{c}$ & $\phi_{\mathrm{st}}$ \\
\hline \multirow[t]{37}{*}{ DEAS } & $0.5205 \pm 0.0280$ & 0.996 & $0.0389 \pm 0.0021$ & $(1.9064 \pm 1.4367)$ \\
\hline & $0.5205 \pm 0.0280$ & 0.989 & $0.3463 \pm 0.0190$ & $0.6091 \pm 0.1634$ \\
\hline & $0.5205 \pm 0.0280$ & 0.973 & $0.7256 \pm 0.0399$ & $(0.6979 \pm 0.0801)$ \\
\hline & $0.5258 \pm 0.0280$ & 0.944 & $1.6153 \pm 0.0887$ & $0.6662 \pm 0.0378$ \\
\hline & $0.5258 \pm 0.0280$ & 0.873 & $3.3483 \pm 0.1841$ & $0.7495 \pm 0.0205$ \\
\hline & $0.5258 \pm 0.0280$ & 0.757 & $5.9851 \pm 0.3290$ & $0.8627 \pm 0.0141$ \\
\hline & $0.5258 \pm 0.0280$ & 0.581 & $10.356 \pm 0.5682$ & $0.9717 \pm 0.0113$ \\
\hline & $0.5258 \pm 0.0280$ & 0.511 & $12.501 \pm 0.6861$ & $0.9951 \pm 0.0108$ \\
\hline & $0.5258 \pm 0.0280$ & 0.284 & $22.366 \pm 0.9986$ & $1.0429 \pm 0.0104$ \\
\hline & $0.9942 \pm 0.0370$ & 0.989 & $0.2780 \pm 0.0135$ & $(0.7361 \pm 0.2028)$ \\
\hline & $0.9942 \pm 0.0370$ & 0.983 & $0.0255 \pm 0.0012$ & $(3.6394 \pm 2.1935)$ \\
\hline & $0.9942 \pm 0.0370$ & 0.982 & $0.5379 \pm 0.0262$ & $0.6365 \pm 0.1059$ \\
\hline & $1.0268 \pm 0.0250$ & 0.962 & $1.2102 \pm 0.0444$ & $0.5976 \pm 0.0481$ \\
\hline & $0.9942 \pm 0.0370$ & 0.956 & $1.2030 \pm 0.0585$ & $(0.6867 \pm 0.0491)$ \\
\hline & $1.0105 \pm 0.0370$ & 0.916 & $2.4981 \pm 0.1212$ & $0.6499 \pm 0.0251$ \\
\hline & $1.0105 \pm 0.0370$ & 0.852 & $4.3347 \pm 0.2100$ & $0.6862 \pm 0.0160$ \\
\hline & $1.0105 \pm 0.0370$ & 0.762 & $7.2647 \pm 0.3503$ & $0.6923 \pm 0.0110$ \\
\hline & $1.0105 \pm 0.0370$ & 0.642 & $12.284 \pm 0.4004$ & $0.6672 \pm 0.0076$ \\
\hline & $1.4600 \pm 0.0840$ & 0.999 & $0.0201 \pm 0.0014$ & $(0.9210 \pm 2.7669)$ \\
\hline & $1.4600 \pm 0.0840$ & 0.993 & $0.2048 \pm 0.0143$ & $0.6042 \pm 0.2745$ \\
\hline & $1.4600 \pm 0.0840$ & 0.983 & $0.4276 \pm 0.0299$ & $0.7566 \pm 0.1342$ \\
\hline & $1.4600 \pm 0.0840$ & 0.965 & $0.9412 \pm 0.0658$ & $0.7072 \pm 0.0631$ \\
\hline & $1.4600 \pm 0.0840$ & 0.919 & $1.9251 \pm 0.1346$ & $0.8153 \pm 0.0337$ \\
\hline & $1.4600 \pm 0.0840$ & 0.850 & $3.2805 \pm 0.2294$ & $0.9144 \pm 0.0225$ \\
\hline & $1.4600 \pm 0.0840$ & 0.746 & $5.3432 \pm 0.3736$ & $1.0147 \pm 0.0168$ \\
\hline & $1.4600 \pm 0.0840$ & 0.640 & $7.9577 \pm 0.3893$ & $1.0377 \pm 0.0128$ \\
\hline & $1.5406 \pm 0.0210$ & 0.963 & $0.9499 \pm 0.0245$ & $0.7411 \pm 0.0609$ \\
\hline & $1.5406 \pm 0.0210$ & 0.920 & $1.9401 \pm 0.0499$ & $0.7952 \pm 0.0314$ \\
\hline & $1.5406 \pm 0.0210$ & 0.851 & $3.3414 \pm 0.0860$ & $0.8934 \pm 0.0198$ \\
\hline & $1.5406 \pm 0.0210$ & 0.750 & $5.5010 \pm 0.1416$ & $0.9691 \pm 0.0138$ \\
\hline & $1.5406 \pm 0.0210$ & 0.647 & $8.3302 \pm 0.1076$ & $0.9683 \pm 0.0104$ \\
\hline & $2.0979 \pm 0.0330$ & 0.968 & $0.7645 \pm 0.0223$ & $(0.7788 \pm 0.0755)$ \\
\hline & $2.0567 \pm 0.0330$ & 0.958 & $0.7650 \pm 0.0225$ & $(1.0377 \pm 0.0764)$ \\
\hline & $2.0773 \pm 0.0330$ & 0.918 & $1.5571 \pm 0.0459$ & $1.0211 \pm 0.0397$ \\
\hline & $2.0773 \pm 0.0330$ & 0.844 & $2.6643 \pm 0.0783$ & $1.1768 \pm 0.0257$ \\
\hline & $2.0773 \pm 0.0330$ & 0.731 & $4.1566 \pm 0.1221$ & $1.3923 \pm 0.0197$ \\
\hline & $2.0773 \pm 0.0330$ & 0.631 & $6.1016 \pm 0.0912$ & $1.3947 \pm 0.0151$ \\
\hline
\end{tabular}




\begin{tabular}{|c|c|c|c|c|}
\hline $\operatorname{amin}$ & ium:sulfate ratio ${ }^{b}$ & $a_{\mathrm{w}}$ & $m \mathrm{SO}_{4}{ }^{2-}\left(\mathrm{mol} \mathrm{kg}^{-1}\right)^{c}$ & $\phi_{\text {st }}$ \\
\hline \multirow[t]{37}{*}{ TMAS } & $0.3977 \pm 0.0220$ & 0.994 & $0.0464 \pm 0.0022$ & $(2.4004 \pm 1.2089)$ \\
\hline & $0.3977 \pm 0.0220$ & 0.985 & $0.4559 \pm 0.0217$ & $0.6134 \pm 0.1249$ \\
\hline & $0.3977 \pm 0.0220$ & 0.966 & $0.9725 \pm 0.0462$ & $0.6516 \pm 0.0604$ \\
\hline & $0.3976 \pm 0.0220$ & 0.924 & $2.1967 \pm 0.1047$ & $0.6703 \pm 0.0287$ \\
\hline & $0.3976 \pm 0.0220$ & 0.802 & $4.8113 \pm 0.2289$ & $0.8501 \pm 0.0162$ \\
\hline & $0.3976 \pm 0.0220$ & 0.588 & $9.1489 \pm 0.4357$ & $1.0740 \pm 0.0126$ \\
\hline & $0.3976 \pm 0.0220$ & 0.299 & $17.866 \pm 0.8513$ & $1.2494 \pm 0.0132$ \\
\hline & $0.3976 \pm 0.0220$ & 0.161 & $27.154 \pm 0.9694$ & $1.2426 \pm 0.0148$ \\
\hline & $0.4646 \pm 0.0060$ & 0.971 & $0.9474 \pm 0.0169$ & $0.5681 \pm 0.0605$ \\
\hline & $0.4646 \pm 0.0060$ & 0.813 & $4.6963 \pm 0.0837$ & $0.8157 \pm 0.0147$ \\
\hline & $0.4646 \pm 0.0060$ & 0.615 & $8.9953 \pm 0.1603$ & $1.0000 \pm 0.0103$ \\
\hline & $0.4646 \pm 0.0060$ & 0.337 & $17.628 \pm 0.3142$ & $1.1406 \pm 0.0096$ \\
\hline & $0.4646 \pm 0.0060$ & 0.190 & $26.937 \pm 0.2515$ & $1.1419 \pm 0.0110$ \\
\hline & $0.8377 \pm 0.0400$ & 0.993 & $0.0371 \pm 0.0018$ & $(3.4993 \pm 1.5104)$ \\
\hline & $0.8377 \pm 0.0400$ & 0.986 & $0.3653 \pm 0.0181$ & $(0.7140 \pm 0.1552)$ \\
\hline & $0.8377 \pm 0.0400$ & 0.971 & $0.7932 \pm 0.0394$ & $0.6865 \pm 0.0731$ \\
\hline & $0.8377 \pm 0.0400$ & 0.943 & $1.7830 \pm 0.0885$ & $0.6090 \pm 0.0340$ \\
\hline & $0.8377 \pm 0.0400$ & 0.869 & $4.7048 \pm 0.2335$ & $0.5507 \pm 0.0144$ \\
\hline & $0.8377 \pm 0.0400$ & 0.577 & $13.008 \pm 0.3975$ & $0.7822 \pm 0.0080$ \\
\hline & $0.8786 \pm 0.0140$ & 0.979 & $0.6725 \pm 0.0171$ & $0.5840 \pm 0.0845$ \\
\hline & $0.8786 \pm 0.0140$ & 0.841 & $4.7657 \pm 0.1211$ & $0.6739 \pm 0.0141$ \\
\hline & $0.8786 \pm 0.0140$ & 0.747 & $7.4545 \pm 0.1894$ & $0.7229 \pm 0.0102$ \\
\hline & $0.8786 \pm 0.0140$ & 0.572 & $13.494 \pm 0.1567$ & $0.7660 \pm 0.0073$ \\
\hline & $1.0405 \pm 0.0360$ & 0.994 & $0.0356 \pm 0.0014$ & $(3.1275 \pm 1.5711)$ \\
\hline & $1.0405 \pm 0.0360$ & 0.991 & $0.1674 \pm 0.0064$ & $(0.9991 \pm 0.3354)$ \\
\hline & $1.0405 \pm 0.0360$ & 0.986 & $0.3351 \pm 0.0127$ & $(0.7599 \pm 0.1686)$ \\
\hline & $1.0405 \pm 0.0360$ & 0.970 & $0.6815 \pm 0.0259$ & $(0.8176 \pm 0.0846)$ \\
\hline & $1.0405 \pm 0.0360$ & 0.947 & $1.5904 \pm 0.0603$ & $0.6295 \pm 0.0374$ \\
\hline & $1.0405 \pm 0.0360$ & 0.879 & $3.4397 \pm 0.1305$ & $0.6938 \pm 0.0189$ \\
\hline & $1.0405 \pm 0.0360$ & 0.777 & $6.4035 \pm 0.2429$ & $0.7303 \pm 0.0118$ \\
\hline & $1.0405 \pm 0.0360$ & 0.670 & $9.0493 \pm 0.1758$ & $0.8188 \pm 0.0095$ \\
\hline & $1.3393 \pm 0.0360$ & 0.979 & $0.6024 \pm 0.0199$ & $0.6623 \pm 0.0945$ \\
\hline & $1.3393 \pm 0.0360$ & 0.909 & $2.3787 \pm 0.0785$ & $0.7421 \pm 0.0261$ \\
\hline & $1.3393 \pm 0.0360$ & 0.882 & $3.0104 \pm 0.0994$ & $0.7741 \pm 0.0214$ \\
\hline & $1.3393 \pm 0.0360$ & 0.759 & $5.5501 \pm 0.1832$ & $0.9208 \pm 0.0137$ \\
\hline & $1.3393 \pm 0.0360$ & 0.657 & $7.8126 \pm 0.1292$ & $0.9937 \pm 0.0111$ \\
\hline & $1.3916 \pm 0.0350$ & 0.977 & $0.6036 \pm 0.0198$ & $(0.7237 \pm 0.0946)$ \\
\hline
\end{tabular}




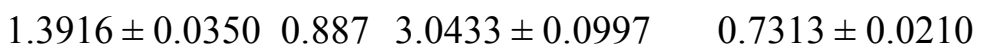

$1.3916 \pm 0.0350 \quad 0.774 \quad 5.6505 \pm 0.1851 \quad 0.8375 \pm 0.0132$

$\begin{array}{llll}1.3916 \pm 0.0350 & 0.679 & 8.0241 \pm 0.1332 & 0.8916 \pm 0.0104\end{array}$

$1.5313 \pm 0.0390 \quad 0.998 \quad 0.0280 \pm 0.0009 \quad(1.1021 \pm 1.986)$

$1.5313 \pm 0.0390 \quad 0.992 \quad 0.1370 \pm 0.0044 \quad(1.0396 \pm 0.4090)$

$\begin{array}{llll}1.5313 \pm 0.0390 & 0.988 & 0.2803 \pm 0.0089 & (0.7969 \pm 0.2009)\end{array}$

$1.5313 \pm 0.0390 \quad 0.980 \quad 0.5569 \pm 0.0177 \quad 0.6599 \pm 0.1021$

$\begin{array}{llll}1.5313 \pm 0.0390 & 0.948 & 1.2766 \pm 0.0406 & 0.7740 \pm 0.0463\end{array}$

$\begin{array}{llll}1.5313 \pm 0.0390 & 0.875 & 2.7080 \pm 0.0862 & 0.9098 \pm 0.0240\end{array}$

$\begin{array}{llll}1.5313 \pm 0.0390 & 0.740 & 4.9449 \pm 0.1575 & 1.1267 \pm 0.0158\end{array}$

$1.5313 \pm 0.0390 \quad 0.682 \quad 5.8864 \pm 0.0800 \quad 1.2030 \pm 0.0141$

$\begin{array}{llll}1.6736 \pm 0.0330 & 0.977 & 0.5587 \pm 0.0162 & 0.7819 \pm 0.1021\end{array}$

$\begin{array}{llll}1.6736 \pm 0.0330 & 0.946 & 1.2893 \pm 0.0374 & 0.8017 \pm 0.0459\end{array}$

$\begin{array}{llll}1.6736 \pm 0.0330 & 0.858 & 2.7610 \pm 0.0801 & 1.0289 \pm 0.0240\end{array}$

$\begin{array}{llll}1.6736 \pm 0.0330 & 0.697 & 5.1187 \pm 0.1485 & 1.3066 \pm 0.0162\end{array}$

$\begin{array}{llll}1.6736 \pm 0.0330 & 0.627 & 6.1684 \pm 0.0750 & 1.4018 \pm 0.0146\end{array}$

$\begin{array}{llll}1.7776 \pm 0.0420 & 0.977 & 0.5628 \pm 0.0192 & 0.7649 \pm 0.1015\end{array}$

$\begin{array}{llll}1.7776 \pm 0.0420 & 0.852 & 2.8240 \pm 0.0965 & 1.0494 \pm 0.0239\end{array}$

$1.7776 \pm 0.0420 \quad 0.685 \quad 5.3263 \pm 0.1819 \quad 1.3160 \pm 0.0162$

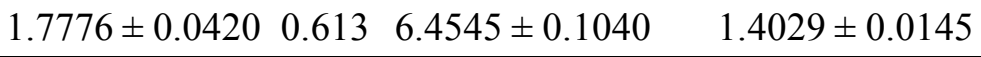

${ }^{a}$ Numbers given in brackets were omitted from the fits of the extended ZSR model.

${ }^{b}$ Molar ratio. ${ }^{c}$ The total sulfate molality in the solution. 
TABLE 2. Parameters of the Extended ZSR Model (Eq. 3), at Fixed Water Activities $\left(a_{\mathrm{w}}\right)$, for Mixtures of Aminium Sulfate Salts and $\mathrm{H}_{2} \mathrm{SO}_{4}$.

\begin{tabular}{|c|c|c|c|c|}
\hline & $a_{\mathrm{w}}$ & $w_{\mathrm{a}}{ }^{\mathrm{o}}$ & $w_{\mathrm{as}}{ }^{\mathrm{o}}$ & $A^{\mathrm{o}}$ \\
\hline \multirow[t]{10}{*}{ MAS } & 0.975 & 1.4725 & $1.5727 \pm 0.2800$ & $-0.769 \pm 0.880$ \\
\hline & 0.95 & 0.7904 & $0.8026 \pm 0.0480$ & $-0.593 \pm 0.180$ \\
\hline & 0.925 & 0.5641 & $0.5647 \pm 0.0200$ & $-0.516 \pm 0.076$ \\
\hline & 0.9 & 0.4496 & $0.4389 \pm 0.0099$ & $-0.430 \pm 0.037$ \\
\hline & 0.85 & 0.3312 & $0.3043 \pm 0.0057$ & $-0.330 \pm 0.021$ \\
\hline & 0.8 & 0.2682 & $0.2335 \pm 0.0060$ & $-0.278 \pm 0.023$ \\
\hline & 0.75 & 0.2276 & $0.1901 \pm 0.0052$ & $-0.250 \pm 0.021$ \\
\hline & 0.7 & 0.1984 & $0.1592 \pm 0.0056$ & $-0.238 \pm 0.022$ \\
\hline & 0.65 & 0.1759 & $0.1357 \pm 0.0047$ & $-0.226 \pm 0.019$ \\
\hline & 0.6 & 0.1578 & $0.1148 \pm 0.0066$ & $-0.208 \pm 0.022$ \\
\hline \multirow[t]{10}{*}{ EAS } & 0.975 & 1.4725 & $1.6755 \pm 0.0200$ & $-0.765 \pm 0.063$ \\
\hline & 0.95 & 0.7904 & $0.8775 \pm 0.0190$ & $-0.615 \pm 0.055$ \\
\hline & 0.925 & 0.5641 & $0.6224 \pm 0.0190$ & $-0.526 \pm 0.054$ \\
\hline & 0.9 & 0.4496 & $0.4795 \pm 0.0160$ & $-0.438 \pm 0.044$ \\
\hline & 0.85 & 0.3312 & $0.3283 \pm 0.0116$ & $-0.353 \pm 0.033$ \\
\hline & 0.8 & 0.2682 & $0.2569 \pm 0.0125$ & $-0.331 \pm 0.034$ \\
\hline & 0.75 & 0.2276 & $0.2051 \pm 0.0099$ & $-0.296 \pm 0.028$ \\
\hline & 0.7 & 0.1984 & $0.1678 \pm 0.0098$ & $-0.266 \pm 0.027$ \\
\hline & 0.65 & 0.1759 & $0.1388 \pm 0.0097$ & $-0.249 \pm 0.027$ \\
\hline & 0.6 & 0.1578 & $0.1185 \pm 0.0089$ & $-0.232 \pm 0.025$ \\
\hline \multirow[t]{8}{*}{ DMAS } & 0.95 & 0.7904 & $0.9017 \pm 0.0330$ & $-0.635 \pm 0.120$ \\
\hline & 0.925 & 0.5641 & $0.6586 \pm 0.0130$ & $-0.606 \pm 0.055$ \\
\hline & 0.9 & 0.4496 & $0.5250 \pm 0.0100$ & $-0.543 \pm 0.042$ \\
\hline & 0.85 & 0.3312 & $0.3796 \pm 0.0083$ & $-0.456 \pm 0.032$ \\
\hline & 0.8 & 0.2682 & $0.3014 \pm 0.0059$ & $-0.416 \pm 0.023$ \\
\hline & 0.75 & 0.2276 & $0.2505 \pm 0.0048$ & $-0.372 \pm 0.020$ \\
\hline & 0.7 & 0.1984 & $0.2139 \pm 0.0054$ & $-0.347 \pm 0.021$ \\
\hline & 0.65 & 0.1759 & $0.1861 \pm 0.0046$ & $-0.325 \pm 0.019$ \\
\hline \multirow[t]{6}{*}{ DEAS } & 0.975 & 1.4725 & $1.9987 \pm 0.1340$ & $-1.528 \pm 0.335$ \\
\hline & 0.95 & 0.7904 & $1.0246 \pm 0.0630$ & $-0.948 \pm 0.180$ \\
\hline & 0.925 & 0.5641 & $0.7269 \pm 0.0510$ & $-0.740 \pm 0.140$ \\
\hline & 0.9 & 0.4496 & $0.5644 \pm 0.0160$ & $-0.607 \pm 0.056$ \\
\hline & 0.85 & 0.3312 & $0.4023 \pm 0.0130$ & $-0.493 \pm 0.046$ \\
\hline & 0.8 & 0.2682 & $0.3178 \pm 0.0130$ & $-0.445 \pm 0.046$ \\
\hline
\end{tabular}


TABLE 3. Fitted Parameters of the Ion Interaction Model (Eq. 4) for the Aminium Sulfate Salts. ${ }^{a}$

\begin{tabular}{lcccc}
\hline & $B_{\mathrm{M}, \mathrm{X}}$ & $W_{\mathrm{w}, \mathrm{MX}}$ & $U_{w, M X}$ & $V_{w, M X}{ }^{c}$ \\
\cline { 2 - 5 } MAS & $-7.5248 \pm 62.6909$ & $-0.9172 \pm 0.1226$ & $4.5909 \pm 0.3043$ & -4.0524 \\
EAS & $25.3847 \pm 99.5183$ & $-1.0045 \pm 0.2158$ & $4.5156 \pm 0.5236$ & -2.3439 \\
DMAS & $-43.3109 \pm 37.9502$ & $-2.8277 \pm 0.2547$ & $6.8415 \pm 0.4641$ & -6.2113 \\
DEAS & $44.6350 \pm 140.0407$ & $-2.5182 \pm 1.5148$ & $6.2800 \pm 2.5315$ & -3.1156 \\
TMAS & $-94.4591 \pm 124.0575$ & $-4.2897 \pm 1.4157$ & $8.3745 \pm 2.3377$ & -5.6426 \\
\hline
\end{tabular}

${ }^{a}$ Values of other coefficients and constants in the equation are: $A^{\phi}=2.917, \alpha=13.0$, and $\rho=13.0 .{ }^{b}$ Parameter uncertainty at $90 \%$ confidence level. ${ }^{c}$ This parameter was constrained artificially and not fitted. 


\title{
Supplementary Information
}

\section{Water Activities and Osmotic Coefficients of Aqueous Solutions of Five Alkyl-Aminium Sulfates and Their Mixtures with $\mathrm{H}_{2} \mathrm{SO}_{4}$ at $25{ }^{\circ} \mathrm{C}$}

\author{
Meike Sauerwein ${ }^{1}$, Simon L. Clegg ${ }^{2, *}$, and Chak K. Chan ${ }^{1,3, *}$ \\ ${ }^{1}$ Division of Environment, Hong Kong University of Science and Technology, Clear Water Bay, \\ Kowloon, Hong Kong \\ ${ }^{2}$ School of Environmental Sciences, University of East Anglia, Norwich NR4 7TJ, U.K. \\ ${ }^{3}$ Department of Chemical Engineering, Hong Kong University of Science and Technology, Clear \\ Water Bay, Kowloon, Hong Kong \\ *Corresponding author: sclegg@uea.ac.uk; keckchan@ust.hk
}

The information in this document is supplementary to the following publication: *****

\begin{abstract}
Notes
The aminium salts studied in this work are: MAS - methylaminium sulfate; EAS - ethylaminium sulfate; DMAS - dimethylaminium sulfate; DEAS - diethylaminium sulfate and TMAS trimethylaminium sulfate.

Throughout this document, the molar aminium:sulfate ratio in the solutions is abbreviated as "A:S". A ratio of 2:1 corresponds to pure aqueous aminium sulfate, and a ratio of $0: 1$ to pure aqueous $\mathrm{H}_{2} \mathrm{SO}_{4}$.
\end{abstract}

\section{Contents}

Table1: Solute molalities at fixed values of the water activity, obtained by interpolation of the experimental results. 
SI TABLE 1. Total sulfate molalities $\left(\mathrm{mSO}_{4}{ }^{2-}\right.$ in $\left.\mathrm{mol} \mathrm{kg}^{-1}\right)$ at fixed water activities $\left(a_{\mathrm{w}, \mathrm{fix}}\right)$ obtained by linear interpolation of the experimental results (as osmotic coefficients vs $\mathrm{V}_{\mathrm{mSO}}{ }_{4}{ }^{2-}$ ). The molar aminium:sulfate ratio $(A: S)$ is listed for each mixture (a value of 0.0 corresponds to pure aqueous $\mathrm{H}_{2} \mathrm{SO}_{4}$, and a value of 2.0 to the pure aqueous aminium sulfate).

\begin{tabular}{llllllll}
\hline & $A: S$ & $a_{\mathrm{w}, \mathrm{fix}}$ & $m \mathrm{SO}_{4}{ }^{2-}$ & & $A: S$ & $a_{\mathrm{w}, \mathrm{fix}}$ & $m \mathrm{SO}_{4}{ }^{2-}$ \\
\hline $\mathrm{MAS}$ & 0.4461 & 0.975 & 0.8349 & 0.8731 & 0.500 & 16.020 \\
& 0.4490 & 0.950 & 1.4102 & 0.8731 & 0.475 & 17.904 \\
0.4490 & 0.925 & 2.1092 & 0.8731 & 0.450 & 18.744 \\
0.4461 & 0.900 & 2.6789 & 1.3618 & 0.975 & 0.7267 \\
0.4461 & 0.850 & 3.6670 & 1.3618 & 0.950 & 1.5584 \\
0.4461 & 0.800 & 4.6047 & 1.3618 & 0.925 & 2.2861 \\
0.4490 & 0.750 & 5.5424 & 1.3618 & 0.900 & 2.9483 \\
0.4490 & 0.700 & 6.5292 & 1.3708 & 0.850 & 4.2721 \\
0.4490 & 0.650 & 7.5324 & 1.3708 & 0.800 & 5.6492 \\
0.4490 & 0.600 & 8.5634 & 1.3708 & 0.750 & 7.0794 \\
0.4490 & 0.550 & 9.5685 & 1.3708 & 0.700 & 8.7304 \\
0.4490 & 0.525 & 10.239 & 1.3708 & 0.650 & 10.490 \\
0.4490 & 0.500 & 10.934 & 1.7819 & 0.975 & 0.6872 \\
0.4490 & 0.475 & 11.659 & 1.7819 & 0.950 & 1.3911 \\
0.4490 & 0.450 & 12.415 & 1.7819 & 0.925 & 1.9936 \\
0.4490 & 0.425 & 13.207 & 1.7819 & 0.900 & 2.5319 \\
0.4490 & 0.400 & 14.038 & 1.7819 & 0.850 & 3.5693 \\
0.8731 & 0.975 & 0.6455 & 1.7819 & 0.800 & 4.6243 \\
0.8851 & 0.950 & 1.4141 & 1.7819 & 0.750 & 5.6769 \\
0.8851 & 0.925 & 2.1883 & 1.7819 & 0.700 & 6.8145 \\
0.8851 & 0.900 & 2.8607 & 1.7819 & 0.650 & 8.0839 \\
0.8851 & 0.850 & 4.1841 & 1.9486 & 0.950 & 1.1708 \\
0.8610 & 0.800 & 5.3437 & 1.9486 & 0.925 & 1.7269 \\
0.8610 & 0.750 & 6.6678 & 1.9486 & 0.900 & 2.2772 \\
0.8851 & 0.700 & 8.1729 & 1.9486 & 0.850 & 3.3746 \\
0.8851 & 0.650 & 9.9331 & 1.9486 & 0.800 & 4.4268 \\
0.8851 & 0.600 & 11.853 & 1.9486 & 0.750 & 5.4883 \\
0.8851 & 0.550 & 13.960 & 1.9486 & 0.700 & 6.5774 \\
& 0.525 & 15.095 & 1.9486 & 0.650 & 7.7558 \\
& & & 1.9486 & 0.600 & 8.9904 \\
\hline
\end{tabular}




\begin{tabular}{llllllllll}
\hline \multirow{2}{*}{$A: S$} & $a_{\mathrm{w}, \mathrm{fix}}$ & $m \mathrm{SO}_{4}{ }^{2-}$ & $A: S$ & $a_{\mathrm{w}, \mathrm{fix}}$ & $m \mathrm{SO}_{4}{ }^{2-}$ & $A: S$ & $a_{\mathrm{w}, \mathrm{fix}}$ & $m \mathrm{SO}_{4}{ }^{2-}$ \\
\hline & 0.4825 & 0.975 & 0.7159 & 0.9454 & 0.600 & 11.329 & 1.4046 & 0.925 & 2.0363 \\
& 0.4847 & 0.950 & 1.4087 & 0.9454 & 0.550 & 13.335 & 1.4046 & 0.900 & 2.6697 \\
& 0.4847 & 0.925 & 2.0617 & 0.9454 & 0.525 & 14.415 & 1.4046 & 0.850 & 3.9349 \\
& 0.4892 & 0.900 & 2.6329 & 0.9454 & 0.500 & 15.553 & 1.4046 & 0.800 & 5.2766 \\
0.4892 & 0.850 & 3.6761 & 1.0099 & 0.950 & 1.4848 & 1.4046 & 0.750 & 6.7583 \\
0.4892 & 0.800 & 4.6780 & 1.0099 & 0.925 & 2.1744 & 1.4046 & 0.700 & 8.4040 \\
0.4870 & 0.750 & 5.6766 & 1.0099 & 0.900 & 2.8515 & 1.4046 & 0.650 & 10.304 \\
0.4870 & 0.700 & 6.7013 & 1.0099 & 0.850 & 4.2592 & 1.4046 & 0.600 & 12.408 \\
0.4870 & 0.650 & 7.7444 & 1.0099 & 0.800 & 5.7141 & 1.2978 & 0.950 & 1.4598 \\
0.4870 & 0.600 & 8.8179 & 1.0099 & 0.750 & 7.2437 & 1.2978 & 0.925 & 2.1155 \\
0.4892 & 0.550 & 10.083 & 1.0099 & 0.700 & 8.8423 & 1.2978 & 0.900 & 2.7580 \\
0.4892 & 0.525 & 10.777 & 1.0099 & 0.650 & 10.899 & 1.2978 & 0.850 & 4.1314 \\
0.4892 & 0.500 & 11.496 & 1.0099 & 0.600 & 13.234 & 1.2978 & 0.800 & 5.6000 \\
0.4892 & 0.475 & 12.245 & 1.0099 & 0.550 & 15.881 & 1.2978 & 0.750 & 7.1871 \\
0.4892 & 0.450 & 13.025 & 1.0099 & 0.525 & 17.345 & 1.2978 & 0.700 & 9.0112 \\
0.4892 & 0.425 & 13.840 & 1.1905 & 0.950 & 1.4416 & 1.2978 & 0.650 & 11.109 \\
0.4892 & 0.400 & 14.696 & 1.1905 & 0.925 & 2.1903 & 1.8372 & 0.975 & 0.6222 \\
0.9454 & 0.975 & 0.7314 & 1.1905 & 0.900 & 2.8649 & 1.8376 & 0.950 & 1.1985 \\
0.9454 & 0.950 & 1.4314 & 1.1905 & 0.850 & 4.2107 & 1.8376 & 0.925 & 1.7005 \\
0.9454 & 0.925 & 2.0633 & 1.1905 & 0.800 & 5.7021 & 1.8376 & 0.900 & 2.2148 \\
0.9454 & 0.900 & 2.6716 & 1.1905 & 0.750 & 7.2602 & 1.8376 & 0.850 & 3.2480 \\
0.9454 & 0.850 & 3.9200 & 1.1905 & 0.700 & 9.1541 & 1.8374 & 0.800 & 4.1539 \\
0.9454 & 0.800 & 5.1988 & 1.1905 & 0.650 & 11.380 & 1.8374 & 0.750 & 5.2513 \\
0.9454 & 0.750 & 6.5438 & 1.1905 & 0.600 & 13.911 & 1.8374 & 0.700 & 6.3944 \\
0.9454 & 0.700 & 7.9398 & 1.4046 & 0.975 & 0.6901 & 1.8376 & 0.650 & 7.7286 \\
0.9454 & 0.650 & 9.4992 & 1.4046 & 0.950 & 1.3912 & 1.8376 & 0.600 & 9.2803 \\
\hline
\end{tabular}

\begin{tabular}{rllllll}
\hline$A: S$ & $a_{\mathrm{w}, \mathrm{fix}}$ & $m \mathrm{SO}_{4}{ }^{2-}$ & & $A: S$ & $a_{\mathrm{w}, \mathrm{fix}}$ & $m \mathrm{SO}_{4}{ }^{2-}$ \\
\hline DMAS 0.4711 & 0.950 & 1.3665 & & 1.4150 & 0.975 & 0.7128 \\
0.4711 & 0.925 & 2.0178 & & 1.4150 & 0.950 & 1.4141 \\
0.4711 & 0.900 & 2.5973 & & 1.4157 & 0.925 & 2.0446 \\
0.4711 & 0.850 & 3.6808 & & 1.4157 & 0.900 & 2.6397 \\
0.4692 & 0.800 & 4.7297 & & 1.4163 & 0.850 & 3.8084 \\
0.4692 & 0.750 & 5.7461 & & 1.4163 & 0.800 & 4.9840 \\
0.4692 & 0.700 & 6.7662 & & 1.4163 & 0.750 & 6.1692 \\
0.4692 & 0.650 & 7.8028 & 1.4163 & 0.700 & 7.4458
\end{tabular}




\begin{tabular}{llllll}
0.4692 & 0.600 & 8.9026 & 1.4163 & 0.650 & 8.7715 \\
0.4692 & 0.550 & 10.182 & 1.9247 & 0.925 & 1.5469 \\
0.4692 & 0.525 & 10.851 & 1.9247 & 0.900 & 1.9511 \\
0.4692 & 0.500 & 11.543 & 1.9247 & 0.850 & 2.7133 \\
0.4692 & 0.475 & 12.260 & 1.9247 & 0.800 & 3.4473 \\
0.4692 & 0.450 & 13.005 & 1.9247 & 0.750 & 4.1695 \\
0.4692 & 0.425 & 13.783 & 1.9247 & 0.700 & 4.8920 \\
0.4692 & 0.400 & 14.595 & 1.9247 & 0.650 & 5.6770 \\
0.9441 & 0.975 & 0.6666 & 1.9579 & 0.975 & 0.5907 \\
0.9441 & 0.950 & 1.4526 & 1.9579 & 0.950 & 1.1100 \\
0.9441 & 0.925 & 2.1818 & 1.9579 & 0.925 & 1.5600 \\
0.9441 & 0.900 & 2.8617 & 1.9579 & 0.900 & 1.9613 \\
0.9541 & 0.850 & 4.2146 & 1.9579 & 0.850 & 2.7162 \\
0.9541 & 0.800 & 5.5983 & 1.9579 & 0.800 & 3.4350 \\
0.9541 & 0.750 & 7.0118 & 1.9579 & 0.750 & 4.1398 \\
0.9541 & 0.700 & 8.6579 & 1.9579 & 0.700 & 4.8434 \\
0.9541 & 0.650 & 10.431 & 1.9579 & 0.650 & 5.5852 \\
0.9541 & 0.600 & 12.338 & & & \\
\hline
\end{tabular}

\begin{tabular}{clllllll}
\hline \multicolumn{1}{c}{$A: S$} & $a_{\mathrm{w}, \mathrm{fix}}$ & $m \mathrm{SO}_{4}{ }^{2-}$ & & $A: S$ & $a_{\mathrm{w}, \mathrm{fix}}$ & $m \mathrm{SO}_{4}{ }^{2-}$ \\
\hline DEAS & 0.5231 & 0.975 & 0.7413 & & 1.0105 & 0.650 & 11.917 \\
& 0.5231 & 0.950 & 1.4376 & 1.4600 & 0.975 & 0.6383 \\
0.5258 & 0.925 & 2.0847 & 1.4600 & 0.950 & 1.2693 \\
0.5258 & 0.900 & 2.7011 & 1.4600 & 0.925 & 1.7963 \\
0.5258 & 0.850 & 3.8793 & & 1.4600 & 0.900 & 2.3047 \\
0.5258 & 0.800 & 5.0082 & 1.4600 & 0.850 & 3.2872 \\
0.5258 & 0.750 & 6.1388 & 1.4600 & 0.800 & 4.2750 \\
0.5258 & 0.700 & 7.3353 & 1.4600 & 0.750 & 5.2638 \\
0.5258 & 0.650 & 8.5657 & 1.4600 & 0.700 & 6.4392 \\
0.5258 & 0.600 & 9.8427 & 1.4600 & 0.650 & 7.6968 \\
0.5258 & 0.550 & 11.266 & 1.5406 & 0.950 & 1.2494 \\
0.5258 & 0.525 & 12.040 & 1.5406 & 0.925 & 1.8263 \\
0.5258 & 0.500 & 12.862 & 1.5406 & 0.900 & 2.3564 \\
0.5258 & 0.475 & 13.747 & 1.5406 & 0.850 & 3.3627 \\
0.5258 & 0.450 & 14.673 & 1.5406 & 0.800 & 4.4223 \\
0.5258 & 0.425 & 15.646 & 1.5406 & 0.750 & 5.4939 \\
0.5258 & 0.400 & 16.670 & 1.5406 & 0.700 & 6.8127
\end{tabular}




\begin{tabular}{llllll}
1.0105 & 0.975 & 0.7528 & 1.5406 & 0.650 & 8.2315 \\
1.0187 & 0.950 & 1.5476 & 2.0773 & 0.900 & 1.8323 \\
1.0187 & 0.925 & 2.2500 & 2.0773 & 0.850 & 2.5787 \\
1.0105 & 0.900 & 2.9542 & 2.0773 & 0.800 & 3.2560 \\
1.0105 & 0.850 & 4.3815 & 2.0773 & 0.750 & 3.9134 \\
1.0105 & 0.800 & 5.9853 & 2.0773 & 0.700 & 4.7374 \\
1.0105 & 0.750 & 7.7174 & 2.0773 & 0.650 & 5.7168 \\
1.0105 & 0.700 & 9.7163 & & & \\
\hline
\end{tabular}

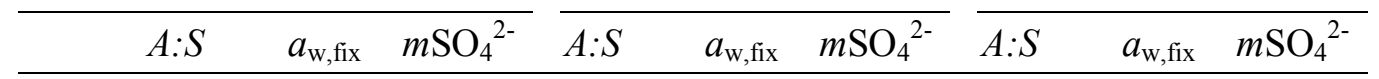

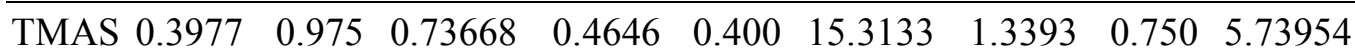

$\begin{array}{llllllllll}0.3976 & 0.950 & 1.43877 & 0.8377 & 0.950 & 1.51281 & 1.3393 & 0.700 & 6.84566\end{array}$

$\begin{array}{llllllllll}0.3976 & 0.925 & 2.15380 & 0.8377 & 0.925 & 2.43117 & 1.3916 & 0.850 & 3.90447\end{array}$

$\begin{array}{llllllllll}0.3976 & 0.900 & 2.73233 & 0.8377 & 0.900 & 3.39960 & 1.3916 & 0.800 & 5.05948\end{array}$

$\begin{array}{llllllllll}0.3976 & 0.850 & 3.81077 & 0.8377 & 0.850 & 5.26663 & 1.3916 & 0.750 & 6.24735\end{array}$

$\begin{array}{llllllllll}0.3976 & 0.800 & 4.84504 & 0.8377 & 0.800 & 6.68383 & 1.3916 & 0.700 & 7.49645\end{array}$

$\begin{array}{llllllllll}0.3976 & 0.750 & 5.84594 & 0.8377 & 0.750 & 8.07663 & 1.5313 & 0.975 & 0.68480\end{array}$

$\begin{array}{llllllllll}0.3976 & 0.700 & 6.84575 & 0.8377 & 0.700 & 9.46925 & 1.5313 & 0.950 & 1.23500\end{array}$

$\begin{array}{llllllllll}0.3976 & 0.650 & 7.85804 & 0.8377 & 0.650 & 10.8803 & 1.5313 & 0.925 & 1.74907\end{array}$

$\begin{array}{llllllllll}0.3976 & 0.600 & 8.89485 & 0.8377 & 0.600 & 12.3265 & 1.5313 & 0.900 & 2.23941\end{array}$

$\begin{array}{llllllllll}0.3976 & 0.550 & 10.0912 & 0.8786 & 0.975 & 0.79568 & 1.5313 & 0.850 & 3.14107\end{array}$

$\begin{array}{lllllllll}0.3976 & 0.525 & 10.7341 & 0.8786 & 0.950 & 1.55066 & 1.5313 & 0.800 & 3.97015\end{array}$

$\begin{array}{llllllllll}0.3976 & 0.500 & 11.3976 & 0.8786 & 0.925 & 2.29066 & 1.5313 & 0.750 & 4.78288\end{array}$

$\begin{array}{llllllllll}0.3976 & 0.475 & 12.0840 & 0.8786 & 0.900 & 3.02425 & 1.5313 & 0.700 & 5.59313\end{array}$

$\begin{array}{llllllllll}0.3976 & 0.450 & 12.7963 & 0.8786 & 0.850 & 4.49032 & 1.6736 & 0.975 & 0.59811\end{array}$

$\begin{array}{llllllllll}0.3976 & 0.425 & 13.5375 & 0.8786 & 0.800 & 5.92840 & 1.6736 & 0.950 & 1.18729\end{array}$

$\begin{array}{llllllllll}0.3976 & 0.400 & 14.3114 & 0.8786 & 0.750 & 7.37643 & 1.6736 & 0.925 & 1.66180\end{array}$

$\begin{array}{llllllllll}0.4646 & 0.950 & 1.52498 & 0.8786 & 0.700 & 8.97821 & 1.6736 & 0.900 & 2.08516\end{array}$

$\begin{array}{llllllllll}0.4646 & 0.925 & 2.15155 & 0.8786 & 0.650 & 10.6651 & 1.6736 & 0.850 & 2.87769\end{array}$

$\begin{array}{llllllllll}0.4646 & 0.900 & 2.74603 & 0.8786 & 0.600 & 12.4471 & 1.6736 & 0.800 & 3.62060\end{array}$

$\begin{array}{llllllllll}0.4646 & 0.850 & 3.88097 & 1.0405 & 0.925 & 2.20637 & 1.6736 & 0.750 & 4.34688\end{array}$

$\begin{array}{llllllllll}0.4646 & 0.800 & 4.97580 & 1.0405 & 0.900 & 2.88065 & 1.6736 & 0.700 & 5.07019\end{array}$

$\begin{array}{llllllllll}0.4646 & 0.750 & 6.04646 & 1.0405 & 0.850 & 4.26437 & 1.6736 & 0.650 & 5.81498\end{array}$

$\begin{array}{llllllllll}0.4646 & 0.700 & 7.12107 & 1.0405 & 0.800 & 5.71286 & 1.7776 & 0.975 & 0.60565\end{array}$

$\begin{array}{llllllllll}0.4646 & 0.650 & 8.21328 & 1.0405 & 0.750 & 7.06151 & 1.7776 & 0.950 & 1.10711\end{array}$

$\begin{array}{llllllllll}0.4646 & 0.600 & 9.38166 & 1.0405 & 0.700 & 8.29918 & 1.7776 & 0.925 & 1.57019\end{array}$

$\begin{array}{llllllllll}0.4646 & 0.550 & 10.7169 & 1.3393 & 0.975 & 0.70060 & 1.7776 & 0.900 & 2.01142\end{array}$ 


\begin{tabular}{lllllllll}
0.4646 & 0.525 & 11.4148 & 1.3393 & 0.950 & 1.35096 & 1.7776 & 0.850 & 2.85491 \\
0.4646 & 0.500 & 12.1360 & 1.3393 & 0.925 & 1.98129 & 1.7776 & 0.800 & 3.61241 \\
0.4646 & 0.475 & 12.8831 & 1.3393 & 0.900 & 2.58843 & 1.7776 & 0.750 & 4.35546 \\
0.4646 & 0.450 & 13.6592 & 1.3393 & 0.850 & 3.67904 & 1.7776 & 0.700 & 5.09736 \\
0.4646 & 0.425 & 14.4679 & 1.3393 & 0.800 & 4.70860 & 1.7776 & 0.650 & 5.86661 \\
\hline
\end{tabular}

